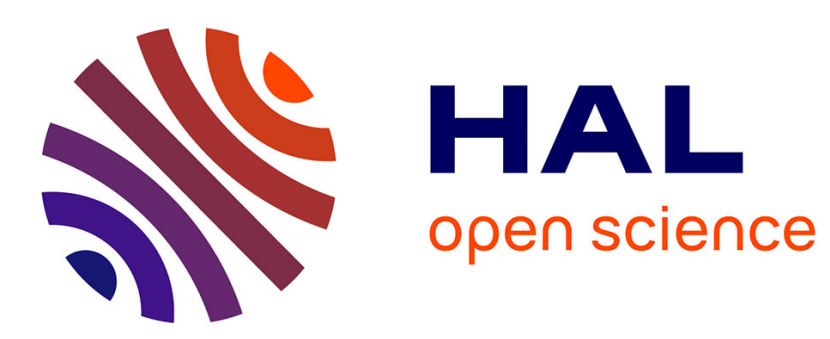

\title{
ANALYSING FLUX DECLINE IN DEAD-END FILTRATION
}

\author{
Alexia Grenier, Martine Meireles, Pierre Aimar, Philippe Carvin
}

\section{To cite this version:}

Alexia Grenier, Martine Meireles, Pierre Aimar, Philippe Carvin. ANALYSING FLUX DECLINE IN DEAD-END FILTRATION. Chemical Engineering Research and Design, 2008, 86, pp.1281-1293. 10.1016/j.cherd.2008.06.005 . hal-00329472

\section{HAL Id: hal-00329472 https://hal.science/hal-00329472}

Submitted on 13 Oct 2008

HAL is a multi-disciplinary open access archive for the deposit and dissemination of scientific research documents, whether they are published or not. The documents may come from teaching and research institutions in France or abroad, or from public or private research centers.
L'archive ouverte pluridisciplinaire HAL, est destinée au dépôt et à la diffusion de documents scientifiques de niveau recherche, publiés ou non, émanant des établissements d'enseignement et de recherche français ou étrangers, des laboratoires publics ou privés. 
Alexia Grenier, Martine Meireles ${ }^{1}$, Pierre Aimar, Philippe Carvin ${ }^{2}$

\author{
Université de Toulouse \\ Laboratoire de Génie Chimique, UMR CNRS 5503 \\ Université Paul Sabatier \\ 118 route de Narbonne \\ 31062 Toulouse Cedex 9, France
}

\section{Abstract}

Can we rely on the analysis of flux decline to evaluate the risks of a filter media to be clogged during filtration of a given particle suspension? This important issue can be dealt with a macroscopic approach described in this paper. We seek to identify and quantify the successive prevailing mechanisms which occur during a filtration run, directly and solely from experimental flux data. This is achieved from the collection of experimental data (filtrate volume $V$ versus time $t$ ) and the use of the differential equation $\frac{d^{2} t}{d V^{2}}=k \cdot\left(\frac{d t}{d V}\right)^{n}$. A methodology is then proposed to define and validate experimental procedures with the purpose of quantifying occurring fouling mechanism. For the purpose of illustrating its valuable impact for a bench marking procedure, the methodology has been applied on a model system composed of a bentonite suspension and a series of microfiltration membranes of different structures.

Keywords: Microfiltration, Flux decline, Blocking, Fouling mechanisms, Filter media

\footnotetext{
${ }^{1}$ Corresponding author : meireles@chimie.ups-tlse.fr

${ }^{2}$ RHODIA Recherche, Centre de Recherche de Lyon, 85 rue des Frères Perret, B.P. 62
} 


\section{Introduction}

3 Microfiltration is a separation process by which some constituents of a suspension are

4 separated from the liquid by a membrane mainly acting as a sieve. Ideally the membrane

5 allows the passage of the fluid through its pores while retaining all suspended solid particles

6 originally present in the fluid. The ideal picture stands if solid particles are all larger than the

7 pores of the membrane and the pore structure consists in capillaries. However in almost all

8 practical cases a fairly wide range of effective particle sizes exists in the feed as well as a

9 random distribution of pores exists in the membrane. In usual cases, when filtering suspensions containing more than a few percents of solids, blocking of particles inside or on

11 the top of the membrane occurs, leading to a reduction in filtration flux. There are four mechanistic models that are generally used to describe fouling ${ }^{1,2}$.

- Complete blocking assumes a seal of pore entrances and the prevention of any flow through them. As pore entrances are sealed, the area open to flow is reduced.

- Intermediate blocking also assumes a seal of pore entrances by a fraction of particles and a deposition of the rest on the top of them.

- Cake filtration is a mechanism by which particles accumulate at the surface in a permeable cake of increasing thickness that adds a hydraulic resistance to filtration.

- Finally standard blocking assumes an accumulation inside the membrane on the pore walls. As the pores are constricted, the membrane permeability is reduced. The mathematical expressions for these laws are summarized in Table 1. These expressions were derived by Hermans and Bredée ${ }^{3}$, on the assumption of separate mechanisms. All these different laws stem from a common differential equation. For a 


$$
\frac{d^{2} t}{d V^{2}}=k\left(\frac{d t}{d V}\right)^{n}
$$
according to Eq. (1). The blocking filtration laws have also been extensively used under their

$6 \quad$ linear form detailed in Table 4.

7 Table 1:

\begin{tabular}{cccc}
$\begin{array}{c}\text { Fouling } \\
\text { mechanism }\end{array}$ & $n$ & $\begin{array}{c}\text { Corresponding linear } \\
\text { form }\end{array}$ & Physical concept \\
\hline $\begin{array}{c}\text { Cake } \\
\text { Filtration }\end{array}$ & 0 & $\frac{d t}{d V}=\frac{1}{Q}=f(V)$ & $\begin{array}{c}\text { Formation of a surface } \\
\text { deposit }\end{array}$ \\
$\begin{array}{c}\text { Intermediate } \\
\text { Blocking }\end{array}$ & 1 & $\frac{d t}{d V}=\frac{1}{Q}=f(t)$ & $\begin{array}{c}\text { Pore blocking + surface } \\
\text { deposit }\end{array}$ \\
$\begin{array}{c}\text { Standard } \\
\text { Blocking }\end{array}$ & 1.5 & $\left(\frac{d V}{d t}\right)^{1 / 2}=Q^{1 / 2}=f(V)$ & Pore constriction \\
$\begin{array}{c}\text { Complete } \\
\text { Blocking }\end{array}$ & 2 & $\frac{d V}{d t}=Q=f(V)$ & Pore blocking
\end{tabular}

9 Each of these mechanisms has been individually invoked alone or in combinations, to explain experimental observations. Most of the time the model which best fits the experimental data is

11 claimed to capture the fouling mechanism.

12 For filtration of BSA proteins suspensions, standard blocking, intermediate blocking or 13 complete blocking models were found to fit the experimental data ${ }^{5}$ with the intermediate model providing the best fit. A combination of standard or complete model and subsequently

15 cake model was also found to fit the data well for the same system ${ }^{6}$. In some other 16 conditions, ${ }^{7}$, it was observed that fouling of microfiltration membranes by BSA did not 17 follow any of the individual models and is more likely described by a combination of several 
1 models. These results show that the predominant mechanisms may vary with operating 2 conditions.

3 Recently a model has been proposed based on a combination of blocking laws in a two-stage

4 mechanism $^{8}$. Fouling initially occurred through complete blocking and subsequently through

5 cake formation. The deposited assemblages were assumed to be permeable so that the flow

6 through the blocked areas also participate to cake formation. The authors found this model

7 provided good data fits for the fouling of microporous track-etched membranes by five 8 proteins. The previous model was further expanded by using a method to combine the four 9 individual blocking laws ${ }^{9}$ The combined models (cake filtration- complete blocking model, 10 cake filtration-standard blocking model) were assessed by testing solutions of bovine serum 11 albumin and human IgG under constant pressure and constant flow modes. The combined 12 cake-complete blocking model provides good fits of both data sets.

13 Combined best fitted models allow a better determination of the membrane capacity, defined 14 as the amount of fluid per membrane are which can be processed until the flux declines to a 15 preset fraction of the initial flux or until the caking starts leading to a several-fold increase in 16 the filtration resistance.

17 Combination of mechanisms has been also been reported for filtration of particles suspensions. For example, the analysis of experimental flux decline during filtration of size distributed carbonyl iron suspensions through woven filter media shows that fouling is

20 initially controlled by standard blocking mechanism prolonged by a cake filtration period ${ }^{1}$.

21 Owing to the impact of porous structure clogging on the lifetime of the filter media, the 22 characterization of the mechanism occurring in the initial period may largely serve to choose 23 the appropriate filter media. An important difficulty lies in the determination at lab scale of 24 this critical initial period. Dilution which extends its duration can be a way but the question 25 may be raised if the same mechanisms occur as for higher solid concentrations. 
2 This works intends to complete previous studies by setting a methodology to analyse 3 experimental flux decline for dead-end filtration runs and identify successive prevailing

4 mechanisms As developed further on, we shall simply assume three types of blocking 5 mechanisms (cake, complete blocking and standard fouling) The methodology can be 6 implemented even in the absence of precise information on the "suspension" or on the filter 7 (for instance, particle size distribution, mean particle diameter, pore size distribution, nominal 8 pore diameter, zeta potential, etc.) and is applicable to various systems (in this paper, we 9 report the results obtained with a bentonite suspension filtered through four microfiltration 10 membranes of different pore size).

11 In our approach, we made the choice of not to describe the transitions between two apparent 12 fouling regimes when two different mechanisms may compete, a point of view which differs 13 from other work ${ }^{8}$, but to approximate the filtration curve into several successive apparent 14 steps during which only one fouling mechanism is predominant. We also made the choice not to dilute the feeds but to develop an appropriate data analysis to capture the initial regime of 16 blocking.

17 In this paper, the main steps of the approach are detailed. Then we see how one could select a filter medium adapted to the filtration of a given suspension and we present how the blocking coefficients deduced with our methodology evolve when parameters such as feed suspension concentration, transmembrane pressure or mean pore diameter change.

\section{Modelling flux decline}

The approach proposed is based on the flux decline analysis. Three types of fouling mechanisms have been considered (cake, complete blocking and standard blocking) leading to

25 a flux decline. Each mechanism is denoted by a specific subscript as : 
1 - (B) for complete blocking defined as particle capture at the 'suspension - filter' interface;

$2-(C)$ for cake formation defined as particle capture at the top surface of the filter (to form a

3 cake or a deposit);

$4 \quad$ - (I) for standard blocking defined as particle capture inside the filter.

6 A series description for the different mechanisms

7 The evolution of the permeate flux, $J$, with filtration time has been modelled by a classical

8 Darcy law ${ }^{10}$ :

$9 \quad J=\frac{\Delta P}{\mu \cdot R}$

10 where $\mathrm{R}$ is a hydraulic resistance.

11 Accordingly, the permeate flux is expressed by:

$12 \quad J=\frac{\Delta P}{\mu \cdot\left(R_{m}+R_{C}\right)}$

13 where $R_{m}$ and $R_{C}$ correspond to the hydraulic resistances of the filter (fouled or not) and the

14 hydraulic resistance of the cake, respectively. As in an unstirred system, we use the classical

15 assumption that the deposit is covering the entire area of the filter.

$16 \quad$ Complete Blocking (B)

17 Concerning the complete blocking mechanism, we use a surface coverage ratio, $\beta_{B}{ }^{8}$.to

18 characterize the surface fraction open to the flow. This ratio may evolve during a certain time

19 and then remains constant when complete blocking is not prevailing anymore. The surface

20 coverage ratio $\beta_{B}$ increases with the cumulative permeate volume, $V$, at a rate characterised by

21 the blocking parameter $\eta_{B}$ : 
$1 \quad \frac{d \beta_{B}}{d t}=\eta_{B} \times J$

2 Equation (4) can also be reformulated as :

$3 \quad \beta_{B}=\eta_{B} \times \frac{V}{A_{0}}$

$4 \quad \eta_{B}$ is the blocked surface area by unit of time and surface of the membrane ( see Appendix I)

5 When a surface blocking prevails, the filter hydraulic resistance, $R_{m, B}$, is directly a function of

$6 \quad \beta_{B}$ according to :

$7 \quad R_{m, B}=\frac{R_{m, 0}}{1-\beta_{B}}$

8 also reformulated as :

$9 \quad R_{m, B}=\frac{R_{m, 0}}{1-\eta_{B} \times \frac{V}{A_{0}}}$

$10 R_{m, 0}$ is the clean membrane hydraulic resistance. It can be calculated from permeability tests

11 on the clean ( non fouled) membrane before any filtration experiment.

12 Cake Formation (C)

13 The cake hydraulic resistance, $R_{C}$, increases with the cumulative permeate volume $V$, at a rate

14 characterised by $\eta_{C}$ for cake formation $(C)$ according to the following equation:

$15 \quad R_{C}=\frac{\eta_{C}}{A_{0}} \times V$

$16 \eta_{C}$ is the volumic specific resistance of the cake ( see Appendix I). 
2 The filter resistance, $R_{m, I}$, increases with the cumulative permeate volume $V$, at a rate

3 characterised by $\eta_{I}$ for internal fouling (I), according to the standard blocking law:

$4 \quad R_{m, I}=\frac{R_{m, 0}}{\left(1-\eta_{I} \times V\right)^{2}}$

$5 \quad \eta_{I}$ is the volume of particle accumulated in the media per unit of permeate volume and per 6 unit of void volume.

7

8

9

10

11 micrometer is about one hundred times the thickness (showing a large shape factor). Their

14 basal face is positively charged, whereas the particle edge is negatively charged.

15

16

17

\subsection{Filter media}

\section{Materials}

\subsection{Suspension}

Bentonite (clay) particles are platelets; the larger dimension of these platelets of about 1 A first suspension was prepared by dispersing $30 \mathrm{~g}$ of clay powder in 1 litre of deionised water. Four settlings (each 4-hour long) lead to a stock suspension of 19 g.L.-1 consisting of micron sized particles. This suspension exhibits a broad particle size distribution around 0.5 $\mu \mathrm{m}$ (see Figure 1) determined by dynamic light scattering experiments (Mastersizer 2000, Malvern Instruments). Suspensions in the concentration range $10^{-3}$ g. $L^{-1}$ to 10 g. $\mathrm{L}^{-1}$ are prepared by dilution of the stock solution with deionised water. 
Four microfiltration membranes have been tested with different nominal pore sizes as

2 provided by manufacturers $(0.2,0.8,5$ and $8 \mu \mathrm{m})$. The 0.2 and $0.8 \mu \mathrm{m}$ membranes are made

3 of cellulose acetate (Schleicher \& Schuell). The 5 and $8 \mu \mathrm{m}$ membranes are made of mixed

4 cellulose esters (Millipore). According to information provided by manufacturers, nominal

5 pore sizes are measured by liquid displacement methods

6

7

8

\subsection{Experimental set-up}

The filtration system is composed of an air-pressurized feed tank connected to a $50-\mathrm{mL}$ filtration cell (Millipore). A fresh membrane is mounted up in the filtration cell and the reservoir is first filled with deionised water. The system is pressurised until a steady state flux is obtained. The cell is then emptied and refilled with the suspension to be filtered. Filtration experiments are conducted at different pressures and different concentrations of suspension without any stirring of the suspension. The permeate is collected in a beaker and the cumulative permeate mass is measured via an electronic balance connected to a computer for on-line data acquisition. At the end of the filtration run, the used microfiltration membrane is discarded and the filtration cell is emptied. For a given set of operating conditions ( feed concentration, transmembrane pressure), the permeate versus volume data are collected from a series of five runs.

\section{Methodology background}

The first objective is to identify which fouling mechanisms are prevailing and when, during a filtration experiment. Even if we do know that fouling phenomena can simultaneously occur, we assume that a filtration run can be split into several successive steps 
1 in which only one fouling mechanism is prevailing. Flux decline analysis requires a rigorous

2 procedure so as to discriminate between the different fouling mechanisms from a

3 differentiation of experimental data such as in equation (1).

4 From a filtration data set, $V(t)$, it is necessary to develop an optimised data post-processing

5 method in order to derive parameters from the $\frac{d^{2} t}{d V^{2}}=f\left(\frac{d t}{d V}\right)$ equations. In order to

6 attenuate the noise in experimental data, a smoothing method is used: the moving average

7 filtering method. It is a low pass filter that averages five neighbouring data. This method

8 proved to be simple and efficient. Lastly, the finite differences method $^{11}$ is used to

9 numerically derive $V(t)$ into $\frac{d^{2} t}{d V^{2}}$ and $\frac{d t}{d V}$.

$11 \quad$ Prevailing fouling mechanisms

12 In Table 1, it has been noticed that a specific value of $n$ characterizes each given fouling 13 mechanism. In the cases for which the value of $n$ found experimentally is different from the 14 ones given in Table 1, we do not have any physical fouling model that corresponds to the flux 15 decline: there may be a combination of several identified or not identified mechanisms.

17 Let us now focus on the exponent $n$. The value of $n$ enables the identification of the controlling fouling mechanisms, whereas the determination of $k$ permits the quantification of

19 the identified fouling mechanism.(see Table 2).

21 Table 2

\begin{tabular}{ccc}
\hline Fouling mechanisms & $k$ & $n$ \\
\hline Cake Filtration & $\frac{\mu \cdot \eta_{C}}{A_{0} \cdot \Delta P}$ & 0
\end{tabular}




$$
\begin{array}{lll}
\text { Standard Blocking } & 2 . \eta_{I} \cdot Q_{o}{ }^{1 / 2} & 1.5 \\
\text { Complete Blocking } & \frac{Q_{0}}{A_{0}} \cdot \eta_{B} & 2
\end{array}
$$

2 According to Figure 2 and Table 3, when $k$ is derived by fitting equation (1) to experimental 3 data, it is greatly influenced by the time step $\Delta t$ used in the differentiating method.

$5 \quad$ Table 3

\begin{tabular}{ccc}
\hline Time step $(\Delta t)$ & $k$ & $n$ \\
\hline $10 \mathrm{~s}$ & $1.4 \times 10^{-2}$ & 2.0 \\
$20 \mathrm{~s}$ & $3.7 \times 10^{-2}$ & 1.9 \\
\hline
\end{tabular}

6

7 Accordingly, it seems more appropriate to use Equation (1) for mechanism identification 8 purposes only (evaluation of $n$ ) but not for quantification (estimation of $k$ ). $k$ will therefore be 9 determined by using the linear form of the models (Table 1).

10 Besides, the use of equation (1) also allows the determination of a range of specific data for 11 which a given mechanism is controlling the flux decline process. The blocking parameters are 12 then evaluated on the data range corresponding to a period of time where the blocking law 13 prevails, which is a key point of this methodology.

14

Determination of blocking parameters

16 Once the data range has been determined for each fouling mechanism, the parameters can be 17 evaluated from the plot of the linear form of the considered fouling mechanism (Table 4).

19 Table 4:

\begin{tabular}{ccc}
\hline Fouling & Linear form & Equation \\
\hline
\end{tabular}




\begin{tabular}{lll}
\hline mechanism & \\
$\begin{array}{c}\text { Cake } \\
\text { Formation }\end{array}$ & $\frac{d t}{d V}=f(V)$ & $\frac{d t}{d V}=\frac{1}{Q_{B, 0} \cdot\left(1-\beta_{B, f}\right)}+\frac{\mu \cdot \eta_{C}}{A_{0}{ }^{2} \cdot \Delta P} \cdot\left(V-V_{C, 0}\right)$ \\
$\begin{array}{ll}\text { Surface } \\
\text { Blocking }\end{array}$ & $\frac{d V}{d t}=Q=f(V)$ & $\frac{Q}{Q_{B, 0}}=1-\beta_{B}=1-\frac{\eta_{B}}{A_{0}} \cdot\left(V-V_{B, 0}\right)$ \\
$\begin{array}{ll}\text { Internal } \\
\text { Fouling }\end{array}$ & $\left(\frac{d V}{d t}\right)^{1 / 2}=Q^{1 / 2}=f(V)$ & $\left(\frac{Q}{Q_{I .0}}\right)^{1 / 2}=1-\eta_{I} \cdot V$ \\
\hline
\end{tabular}

1

\section{Approximation of the filtration in several successive fouling regimes}

As for an example, for the 'bentonite- $.5 \mu \mathrm{m}$ membrane' system (Figure 3), this method allows to identify two fouling regimes

- A very low fouling ( $V L F)$ regime, in our description the flow rate is indeed assumed to remain constant. We use the average value over the time period (Step I). This duration is actually an approximation since the permeate flow rate slightly decreases during this period (Figure 4). But according to the $\frac{d^{2} t}{d V^{2}}=f\left(\frac{d t}{d V}\right)$ representation, the slope $n$ is greater than 2 for this period and it is therefore not possible to refer to a well identified fouling mechanism. We came to suppose that this period may correspond to the deposit of the few first particles having some pore bridging effect; since the mean pore diameter is larger than the mean particle diameter; $r$

- surface blocking or pore blocking $(B)$ regime for which the fouling behaviour is dominated by the complete pore blocking phenomenon (Step II) $(n=2)$; in this regime we calculate the value of $\eta_{B}$ by fitting experimental data with equation (11)( Figure 4);

- cake filtration $(C)$ regime for which the fouling behaviour is dominated by the buildup of a deposit at the top surface of the filter media (Step III) $(n=0)$. in this regime we 
3 When the mean pore diameter is close to the mean particle diameter, we often observe the last two steps (Steps II and III). When the mean pore diameter is much smaller than the mean particle diameter, only cake filtration $(C)$ appears to control flux decline from the very beginning. (Step III)..

\section{Methodology approximations}

Splitting the experimental filtration curve into several successive mechanisms might be a rough approximation as commented before. To make an assessment of the approach, we seek to rebuild the filtration curve from the equations presented in the previous section, and from

11 the parameters derived from experimental data. This step is not a compulsory step of the methodology but a test ensuring that approximations do not introduce significant bias in the quantification of blocking parameters.

For the ' $V L F$ ' period, the constant flow rate is taken as the average between the initial flow rate $\left(Q_{0}\right)$ when the membrane is clean (flow rate measured before the filtration run) and the flow rate $\left(Q_{B, 0}\right)$, the y-intercept of the plot of $Q$ vs. $\left(V-V_{B, 0}\right)$ for the pore blocking regime (Figure 4).

In order to determine the transition between the pore blocking regime and the cake formation regime, two straight lines ( $n=2$ and $n=0$ (plateau)) can be drawn ( Figure 3).. If we extrapolate these two lines, we consider their intersection determines a transition between the 21 two regimes.

22 We then compare the data calculated by approximation in successive fouling regimes with the experimental data. We show the comparison for some given operating conditions in Figure 5:

24 a suspension concentration of $10^{-2}$ g.L $\mathrm{L}^{-1}$ and a transmembrane pressure of $0.3 \mathrm{bar}$, for the four 25 membranes covering a large spectrum of pore sizes (from 0.2 to $8 \mu \mathrm{m}$ ).. 
1 Figure 5 shows the plot of experimental and calculated curves for the four membranes.

2 The methodology gives quite good results for $0.2 \mu \mathrm{m}, 5$ and $8 \mu \mathrm{m}$ membranes, as the

3 calculated curves are very close to the experimental points. The difference between

4 experimental curve and calculated curve for $0.8 \mu \mathrm{m}$ membrane is close to $15 \%$ which is still 5 acceptable.

$6 \quad$ Methodology robustness

7 According to the model, $\beta_{B, f}$ can be estimated as described above by fitting experimental data 8 with a linear form for the blocking law in the cake filtration regime But it can also be 9 evaluated from $\eta_{B}$ as calculated from the experimental flow rate decline in the surface 10 blocking regime and from the difference $V_{B, f}-V_{B, 0}$, according to the expression:

$11 \quad \beta_{B, f}=\frac{\eta_{B}}{A_{0}} \cdot\left(V_{B, f}-V_{B, 0}\right)$

$V_{B, 0}$ and $V_{B, f}$ respectively correspond to the first and the last experimental points of the defined 13 range for which pore blocking regime is dominant $(n=2)$.

14 In Figure 6, we compared the values of $\beta_{B, f}$ determined from the first procedure ( exp) and 15 from the second one ( calc.). The values obtained with both procedures are very close to each 16 other. We can conclude a good agreement between parameters determined in the surface 17 blocking dominant regime with those determined on the experimental data range for which 18 the cake filtration regime is dominant. From this result, we can deduce that our methodology 19 is able to describe the fouling phenomena occurring during a filtration run even though the 20 transition periods have been neglected.

21 In the second part of the paper we shall describe how blocking parameters $\left(\beta_{B, f}, \eta_{B}, \eta_{c}\right)$ 22 correlate to filter type and operating parameters, such as transmembrane pressure or feed concentration. 


\section{$1 \quad$ 5. Results and analysis}

\section{1. $\quad$ Choice of a filter medium}

4 When having to filter a given suspension, the industrial issue is often to get or maintain the

5 highest flow rate at a fixed transmembrane pressure. Whenever filtration is used to collect and

6 concentrate valuable solids, cake formation can be considered as a production regime. The

7 fouling of the filter medium, occurring before or during production is detrimental to the 8 process efficiency. The selection of the filter medium should therefore primarily be based on

9 these filter fouling issues only.

11 In this work, we run three series of filtration experiments with a bentonite suspension through

12 different microfiltration membranes. Blocking of the filter surface then cake formation onto 13 the filter media were the two main successive fouling regimes which were identified by the 14 methodology.

15 One can consider that cake formation does not contribute to filter fouling. However, the cake 16 filtration generates a flux resistance, whose effect is to decrease the filtration process 17 productivity. Its quantification is then worth to be known.

18 The $\left(\eta_{c}\right)$ parameter is an intrinsic characteristic of the filtration cake as we observe the same 19 variations with suspension concentration and pressure, whatever the microfiltration 20 membrane).Therefore, it does not help at selecting the best filter media.

21 The $\left(\eta_{B}\right)$ parameter characterises the rate of surface blocking by a particle, whereas the 22 surface parameter, $\beta_{B}$, quantifies the surface coverage, and $\beta_{B, f}$ quantifies the coverage at the 23 end of the blocking regime. 
1 These parameters are linked by the relation $\beta_{B, f}=\frac{\eta_{B}}{A_{0}} \cdot\left(V_{B, f}-V_{B, 0}\right)$ (Eq. (13)) but they do not

2 show the same trends towards a variation (increase or decrease) of an operating or system

3 parameter. The study of the pore diameter effect shows that using a filter, whose mean pore

4 diameter is close to the mean particle diameter is obviously to be avoided.

5 The knowledge of the particle size distribution of a suspension to be filtered is often useful to

6 avoid choosing certain filter types which could lead to severe media blocking, but this criteria

7 cannot remain the only basis

9 Our goal is to choose a filter whose flux resistance at the end of the blocking regime (before

10 starting the cake filtration regime), $R_{m B, f}=\frac{R_{m, 0}}{1-\beta_{B, f}}$, has the smallest value.

11 Therefore, the characteristics of the "best" filter can be:

- a low clean filter media resistance $R_{m, 0}$;

- a low surface coverage ratio $\beta_{B, f}$ at the end of the blocking regime;

- or the best compromise between both parameters.

In Figure 7 , we plotted $\left(V_{B, f}-V_{B, 0}\right)$ versus $\eta_{B}$, for a series of data for which the pore diameter effect has been studied $\left(\mathrm{d}_{\text {pore }}=0.2 ; 0.8 ; 5 ; 8 \mu \mathrm{m}\right)$. Operating conditions were kept the same for all these experiments: $C=10^{-2} \mathrm{~g} \cdot \mathrm{L}^{-1}, \Delta P=0.3$ bar.

Only the $0.2 \mu \mathrm{m}$ membrane displays a 'high' filtering surface open to the flow, close to $50 \%$, before the beginning of the regime dominated by the "cake formation". The three other membranes are very sensitive to fouling by surface blocking mechanism as their fraction of surface open to flow is below $25 \%$ at the end of the blocking regime. The knowledge of the $\eta_{B}$ is therefore not sufficient to choose between different filter media as a low $\eta_{B}$ parameter does not necessarily indicate a low fouling. Indeed, $R_{m B, f}$, the fouled filter media resistance at 
1 the end of the blocking regime, is a key parameter in the filtration process. Figure 8 shows

2 two curves:

3 - the clean filter media resistance $R_{m, 0}$ versus $\mathrm{d}_{\text {pore }}(\circ)$;

$4 \quad$ - the fouled filter media resistance $R_{m B, f}$ versus $\mathrm{d}_{\text {pore }}(\bullet)$.

5 In Figure 8, the data which correspond to the 5 and $8 \mu \mathrm{m}$ membranes are not considered in the

6 following discussion as we already know that a membrane whose mean pore diameter is way

7 greater than the particle size distribution should be avoided.

8 Usually, the choice of a filter media is usually made on the sole basis of the knowledge of the

9 clean filter media resistance, $R_{m, 0}$, value. In Figure 8 , we can note that the $0.2 \mu \mathrm{m}$ membrane

10 has a clean filter media resistance which is higher than the one of the $0.8 \mu \mathrm{m}$ membrane

11 whereas, at the end of the blocking regime period, the former membrane displays a flux

12 resistance which is lower than the one of the latter. We can then deduce that the $0.2 \mu \mathrm{m}$

13 membrane is the best compromise and is able to maintain a good productivity during the cake

14 formation.

15

16 In short, the choice of a filter media, based on the methodology developed in this paper,

17 remains on the combination of three key parameters:

$18 \quad-\quad$ the clean filter media resistance $R_{m, 0}$;

$19 \quad-\quad$ the $\eta_{B}$ parameter;

20 - the filtrate volume during the blocking phase, $\left(V_{B, f}-V_{B, 0}\right)$.

$22 \quad$ 5.2. Blocking parameters variations when changing operating parameters 
In this section, we focus on parameters variations for the system 'bentonite suspension

2 - cellulose MF membrane' with the two main mechanisms: complete blocking and cake 3 formation.

\subsubsection{Effect of feed concentration}

6 We conducted filtration experiments for a wide range of feed concentrations, from $10^{-3}$ to 10 7 g.L ${ }^{-1}$. The transmembrane pressure was set to 0.3 bar.

9 Figure 9 shows the increase in $\eta_{C}$ the volumic specific resistance of the cake with bentonite 10 concentration for the four membrane pore diameters. A correlation can be determined: $\eta_{C}=$ $117,2.10^{14} \times C^{1.1}$, whatever the studied membrane. which indicates that the value thus obtained 12 characterizes the cake structure, and id independent on the filter characteristics.

13 As shown in Figure 10, $\eta_{B}$ also increases with the suspension concentration but in a nonlinear 14 way. This response could be explained by the presence of some interactions between the particles and the filter media surface (when the concentration of particles is doubled, the $\eta_{B}$ value is not necessarily doubled) and particles steric hindrance at the pores entrance. Besides, two zones can be distinguished according to the ratio of $d_{\text {pore }}$ (pore diameter) to $d_{p}$ (mean particle diameter): the systems for which $d_{\text {pore }} \leq d_{p}$ and those for which $d_{\text {pore }}>d_{p}$. We defined $\psi_{p / p o r e}$ as the ratio of pore to particle projected surfaces (assuming spherical particles). Physically; it represents the number of blocked pores quantity per blocking particle

21 when pore size is smaller than particle size..

$22 \quad \psi_{p / \text { pore }}=\left(\frac{d_{p}}{d_{\text {pore }}}\right)^{2}$ when $d_{\text {pore }}>d_{p}$, whereas $\psi_{p / \text { pore }}=\left(\frac{d_{\text {pore }}}{d_{p}}\right)^{2}$ when $d_{\text {pore }} \leq d_{p}$. 
1 When $\eta_{B}$ is plotted versus $C \times \psi_{p / \text { pore }}$ (Figure11), data follow a same trend for concentrations

2 below 1 g.L $\mathrm{L}^{-1}$. But for concentrations above $1 \mathrm{~g} \cdot \mathrm{L}^{-1}$, interactions between particles may play a 3 more significant role.

\subsubsection{Effect of transmembrane pressure}

7 The effect of transmembrane pressure on cake filtration parameter is investigated for the 8 range $0.03-1.2$ bar. Two membranes are considered: $0.2 \mu \mathrm{m}$ and $C=0.1 \mathrm{~g} / \mathrm{L} ; 8 \mu \mathrm{m}$ and $C=$ $9 \quad 1 \mathrm{~g} / \mathrm{L}$. Since $\left(\eta_{C}\right)$ is proportional to $C^{1.1}$, the sets of data for the two pore diameters $(0.2$ and 8 $10 \mu \mathrm{m})$ can be normalised by dividing $\left(\eta_{C}\right)$ by $C^{1.1}$ (see $\S 6.2 .1$.). Data then fall on the same line 11 (Figure 12) which confirms that cake filtration is not influenced by the mean pore diameter of 12 the filter media.

13 As shown in Figure 13, $\left(\eta_{B}\right)$ decreases when the transmembrane pressure increases for both 14 membranes $(0.2$ and $8 \mu \mathrm{m})$. In Figure 13 , for the $8 \mu \mathrm{m}$ membrane, the value of $\left(\eta_{B}\right)$ is high $15\left(1500 \mathrm{~m}^{-1}\right)$ for very low transmembrane pressure, whereas it is much lower for the higher pressures. This shows that bentonite particles have a strong tendency to stick to the membrane

17 pores at low filtration rate. The trend is different for the $0.2 \mu \mathrm{m}$ membrane. As the mean particle diameter is here four times greater than the mean pore diameter, the filtration rate has a weak effect, compared to the $8 \mu \mathrm{m}$ membrane.

20 From these data, we see that when increasing the transmembrane pressure, a decrease of the $21 \eta_{B}$ value has been observed .The shear stress, $\tau_{w}$, at the pore entrance should be considered in 22 order to explain these observed variations. For a cylindrical pore, the shear stress, $\tau_{w}$, at the 23 pore entrance is a function of the pore diameter, $d_{\text {pore }}$, the fluid flow rate at the pore mouth, $\bar{v}$, 24 and the fluid viscosity, $\mu$. 
$1 \quad \tau_{w}=\frac{8 \mu \bar{\nu}}{d_{\text {pore }}}$

3 According to equation (14), we calculated the shear stresses (see Table 5) corresponding to

4 filtration experiments .

5 Table 5:

6

\begin{tabular}{cccccc}
\hline $\mathrm{d}_{\text {pore }}(\mu \mathrm{m})$ & $\Delta P(\mathrm{~Pa})$ & $Q_{B, 0}\left(\mathrm{~m}^{3} \cdot \mathrm{s}^{-1}\right)$ & $\bar{v}\left({\left.\mathrm{~m} . \mathrm{s}^{-1}\right)}\right.$ & $\mathrm{Re}$ & $\tau_{w}(\mathrm{~Pa})$ \\
\hline $\mathbf{0 . 2}$ & 120,000 & $5.45 \times 10^{-7}$ & $5.08 \times 10^{-4}$ & $1.02 \times 10^{-4}$ & 20 \\
& 30,000 & $3.67 \times 10^{-7}$ & $3.42 \times 10^{-4}$ & $6.84 \times 10^{-5}$ & 14 \\
& 3,000 & $4.51 \times 10^{-8}$ & $4.20 \times 10^{-5}$ & $8.40 \times 10^{-6}$ & 1.7 \\
\hline $\mathbf{8}$ & 120,000 & $3.01 \times 10^{-6}$ & $2.81 \times 10^{-3}$ & $2.25 \times 10^{-2}$ & 2.8 \\
& 60,000 & $2.48 \times 10^{-6}$ & $2.31 \times 10^{-3}$ & $1.85 \times 10^{-2}$ & 2.3 \\
& 30,000 & $1.83 \times 10^{-6}$ & $1.70 \times 10^{-3}$ & $1.36 \times 10^{-2}$ & 1.7 \\
& 9,000 & $8.02 \times 10^{-7}$ & $7.48 \times 10^{-4}$ & $5.98 \times 10^{-3}$ & 0.75 \\
& 3,000 & $9.47 \times 10^{-8}$ & $8.83 \times 10^{-5}$ & $7.07 \times 10^{-4}$ & 0.09 \\
& & & & & \\
\hline
\end{tabular}

7

8 In Figure 14, we have plotted $\eta_{B}$ versus the wall shear stress, $\tau_{w}$. At low wall shear stress, $\eta_{B}$

9 has a high value, and conversely. This result is in good accordance with the fact that the effect

10 of a high wall shear stress at the pore entrance is to lift particles captured at the membrane

11 surface, in other words, to decrease the total amount of particles actually stick to in the filter

12 media.

13 Also, a threshold value for the wall shear stress ( $\tau_{w} \cong 2 \mathrm{~Pa}$ ) appears in Figure 14, above which

$14 \eta_{B}$ tends to stabilize when the transmembrane pressure increases. The data for the $0.2 \mu \mathrm{m}$ are 
1 all above the threshold value, which explains why the pore blocking mechanism is not as

2 much affected by an increase of transmembrane pressure as it is for the $8 \mu \mathrm{m}$ membrane As

3 the average size of bentonite particle is around $0.5 \mu \mathrm{m}$; it can be expected that hydrodynamics

4 will only play a role when particle size are smaller than pores. Accounting for the shear stress

5 in the pore sheds some light, and some details on the physics of the particle capture efficiency

6 in this system.

7

\subsubsection{Effect of pore diameter}

9

10 Four microfiltration membranes have been tested $\left(\mathrm{d}_{\text {pore }}=0.2,0.8,5\right.$ and $\left.8 \mu \mathrm{m}\right)$.

11 Transmembrane pressure was set at 0.3 bar and the feed suspension concentration, $C$, at $10^{-2}$ 12 g. $\mathrm{L}^{-1}$.

13 If we now consider the effect of the mean pore diameter on $\eta_{B}$, Figure 15 shows a maximum

14 for the $0.8 \mu \mathrm{m}$ membrane for which $\mathrm{d}_{\text {pore }} \approx \mathrm{d}_{\mathrm{p}}$. This result confirms the fact that a maximum of fouling by pore blocking can be reached when using a filter media with a mean pore diameter close to the mean diameter of the particles of the suspension to be filtered.

17 We qualitatively compare Figure 15 to the particle size distribution of the bentonite 18 suspension presented in Figure 1. According to Figure 1, the quantity $C_{B}$, the concentration of all the particles which block pores of diameter $d_{\text {pore }}$, is lower for $d_{\text {pore }}=0.2 \mu \mathrm{m}$ than for $d_{\text {pore }}=$ $0.8 \mu \mathrm{m}$. Figure 15 could be interpreted as the variation of $C_{B}$ with the mean pore diameter

$21 d_{\text {pore }}$ : the concentration of the potential particles which plug pores of diameter $d_{\text {pore }}$ varies 22 when using different membranes for a same given suspension.

\section{Conclusions}


A phenomenological approach, which includes a qualitative identification of the main

2 fouling mechanisms prior to a quantitative determination of parameters (blocking parameters)

3 characterising the "suspension-filter" system, allows a rather good description of the flux

4 decline and underlying fouling mechanisms during filtration of a particle suspension. We

5 have considered here the filtration of a bentonite suspension on several microfiltration

6 membranes over a wide range of feed concentrations and transmembrane pressures.

7 This work is based on splitting the fouling analysis into two steps: one is dedicated to 8 the identification of the prevailing fouling mechanisms, and the fraction of process they control. This one much preferably will use equation (1), and the concept of capture efficiency.

The second step uses the integrated form of equation (1) and is aimed at finding the values of the model parameters, for each fouling mechanism.

Even if several fouling phenomena may simultaneously occur, the assumption of successive prevailing fouling mechanisms used here enables a good description of flux decline during a filtration run. The good agreement between experimental and calculated data over wide ranges of operating parameters is a favourable indication of the robustness to this approach, even though the level of description of the filter-suspension system was kept as low as possible all along which makes this approach quite a valuable one for complex systems such as industrial suspension. As a matter of fact, time and volume filtered are the only basic data used. Correlation to other information regarding the filter (pore size) or the suspension (concentration, particles size distribution) is possible, but not necessary.

21 In the systems tested here, we identified two prevailing mechanisms namely surface blocking 22 and cake filtration. A valuable further step would be to extend this work to other systems implying pore blocking as well as internal fouling by testing various "suspension-filter" pairs. An original finding was that surface blocking may considerably reduce the filtering surface open to flow, as up to $80 \%$ of the filter surface could get blinded at the end of the blocking 
1 regime. Phenomenological correlations between blocking parameters for internal, surface or

2 cake blocking mechanisms and operating parameters such as feed concentration or pressure 3 give first insights into physical aspects which rule the particle trapping in different locations 4 of the filter. Such an approach should also be useful to develop more physical models for 5 blocking phenomena.

6

7

\section{Acknowledgements}

9 We would like to thank Rhodia Recherche for its financial support and its technical 11 expertise.

12 


\section{References}

2

3 [1] Grace H.P., Structure and performance of filter media. I. The internal structure of filter media, AIChE J., 2 (1956) 307-315.

[2] Hermia J, Etude analytique des lois de filtration à pression constante, Rev. Univ. Mines., 2 (1966) 45.

[3] Hermans P.H. and Bredée H.L., Principles of the mathematical treatment of constant pressure filtration, J. Soc. Chem. Ind. (1936) 1-4.

[4] Hermia J., Constant pressure blocking filtration laws. Application to power-law nonnewtonian fluids, Trans. I. Chem. E., 60 (1982) 183.-187

[5] Hlavacek M. Bouchet F. , Constant flowrate blocking laws and an example of their application to dead end microfiltration of protein solutions, J. Memb. Sci.., 82 (1993) 285.297.

[6] Tracey E.M. and Davis R.H., Protein fouling of track-etched polycarbonate microfiltration membranes, J. Colloid Interface Sci., 167 (1994) 104-116.

[7] Bowen W.R., Calvo J.I., Hernandez A, Steps of membrane blocking in flux decline during protein microfiltration, J. Membr. Sci., 101 (1995) 153-165.

[8] Ho C.-C. and Zydney A.L., A combined pore blockage and cake filtration model for protein fouling during microfiltration, J. Colloid Interface Sci., 232 (2000) 389-399.

[9] Combined models of membrane fouling: development and application to microfiltration and ultrafiltration of biological fluids, J. Memb. Sci., 277 (2006) 75-84.

[10] Darcy H., Les fontaines publiques de la ville de Dijon; Victor Dalmont, Paris, 1856.

[11] Constantinides A., Finite difference methods, in Applied Numerical Methods with Personal Computers, McGraw-Hill Book Company, New York, NY, 1987, pp. 275-319. 


\section{List of Symbols}

3

$4 \quad A_{0} \quad$ total membrane surface area $\left(\mathrm{m}^{2}\right)$

$5 \quad A_{B} / m_{B} \quad$ blocked surface area of the membrane per unit of blocking particle mass $\left(\mathrm{m}^{2} \cdot \mathrm{kg}^{-1}\right)$

$6 \quad C \quad$ feed suspension concentration $\left(\mathrm{kg} \cdot \mathrm{m}^{-3}\right)$

$7 \quad C_{v} \quad$ volume of the particles which uniformly deposit along the pore wall per unit of

$8 \quad$ permeate volume (dimensionless)

$9 \quad d_{p} \quad$ mean particle diameter $(\mathrm{m})$

$10 \quad d_{\text {pore }} \quad$ pore diameter $(\mathrm{m})$

$11 k$ multiplicative constant in Eq. (1) $\left(\mathrm{s}^{1-n} \cdot \mathrm{m}^{3 n-6}\right)$

$12 J \quad$ permeate flux $\left(\mathrm{m}_{\mathrm{s}} \mathrm{s}^{-1}\right)$

$13 \quad m_{C} \quad$ deposit mass per unit of membrane surface $\left(\mathrm{kg} . \mathrm{m}^{-2}\right)$

$14 \quad$ exponent in Eq. (1) (dimensionless)

$15 \Delta P \quad$ transmembrane pressure $(\mathrm{Pa})$

$16 Q \quad$ permeate flow rate $\left(\mathrm{m}^{3} \cdot \mathrm{s}^{-1}\right)$

$17 Q_{B, 0} \quad$ permeate flow rate at the start point of pore blocking $\left(\mathrm{m}^{3} \cdot \mathrm{s}^{-1}\right)$

$18 Q_{I, 0} \quad$ permeate flow rate at the start point of internal fouling $\left(\mathrm{m}^{3} \cdot \mathrm{s}^{-1}\right)$

$19 Q_{0} \quad$ initial permeate flow rate $\left(\mathrm{m}^{3} \cdot \mathrm{s}^{-1}\right)$

20 Re Reynolds number (dimensionless)

$21 \quad R \quad$ hydraulic resistance in Darcy's law $\left(\mathrm{m}^{-1}\right)$

$22 \quad R_{C} \quad$ cake hydraulic resistance $\left(\mathrm{m}^{-1}\right)$

$23 \quad R_{m} \quad$ membrane hydraulic resistance $\left(\mathrm{m}^{-1}\right)$

$24 \quad R_{m B} \quad$ fouled membrane hydraulic resistance by pore blocking $\left(\mathrm{m}^{-1}\right)$

$25 R_{m B, f} \quad$ final fouled membrane hydraulic resistance by pore blocking $\left(\mathrm{m}^{-1}\right)$ 
$2 R_{m, 0} \quad$ clean membrane hydraulic resistance $\left(\mathrm{m}^{-1}\right)$

$3 \quad R_{m I} \quad$ fouled membrane hydraulic resistance by internal fouling $\left(\mathrm{m}^{-1}\right)$

4

$5 \quad V \quad$ total volume permeated through the membrane at time $\mathrm{t}\left(\mathrm{m}^{3}\right)$

$6 \quad V_{B, 0} \quad$ permeate volume value at the start point of pore blocking $\left(\mathrm{m}^{3}\right)$

$7 \quad V_{B, f} \quad$ permeate volume value at the end of pore blocking $\left(\mathrm{m}^{3}\right)$

$8 V_{C, 0} \quad$ permeate volume value at the start point of cake filtration $\left(\mathrm{m}^{3}\right)$

$9 \quad \bar{v} \quad$ fluid velocity at the pore entrance $\left(\mathrm{m} \cdot \mathrm{s}^{-1}\right)$

$10 t \quad$ time $(\mathrm{s})$

11

12 Greek letters

$13 \alpha \quad$ specific resistance of the cake $\left(\mathrm{m}^{\mathrm{kg}} \mathrm{kg}^{-1}\right)$

$14 \beta_{B} \quad$ surface coverage ratio for pore blocking (dimensionless)

$15 \beta_{B, f} \quad$ final surface coverage ratio at the end of the pore blocking regime (dimensionless)

$16 \quad \varepsilon_{m} \quad$ membrane porosity (dimensionless)

$17 \quad \varepsilon_{C} \quad$ cake porosity (dimensionless)

$18 \quad \eta_{B} \quad$ blocked surface area by unit of time and surface $\left(\mathrm{m}^{-1}\right)$

$19 \quad \eta_{C} \quad$ cake volumic specific resistance $\left(\mathrm{m}^{-2}\right)$

$20 \quad \eta_{I} \quad$ vol. of particle accumulated per unit of permeate and unit of void volume $\left(\mathrm{m}^{-3}\right)$

$21 \mu \quad$ permeate dynamic viscosity (Pa.s)

$22 \rho \quad$ permeate density $\left(\mathrm{kg} \cdot \mathrm{m}^{-3}\right)$

$23 \quad \rho_{p} \quad$ particle density $\left(\mathrm{kg} \cdot \mathrm{m}^{-3}\right)$

$24 \tau_{w} \quad$ shear stress ate the pore entrance $(\mathrm{Pa})$ 
$\psi_{p / p o r e} \quad$ blocked pores quantity by one blocking particle (dimensionless)

2

3 


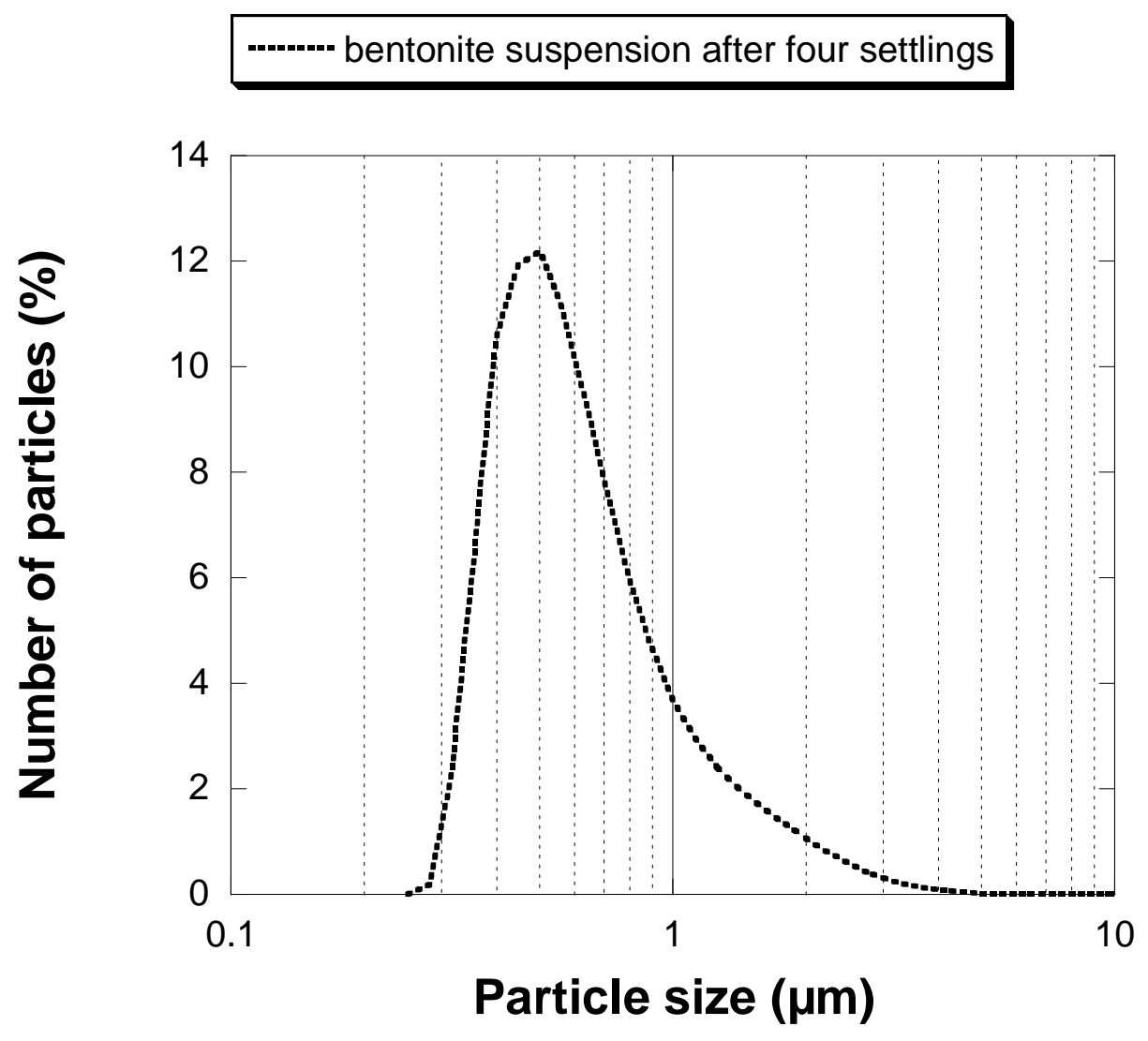

Figure 1. Particle size distribution of a bentonite suspension after four settlings 


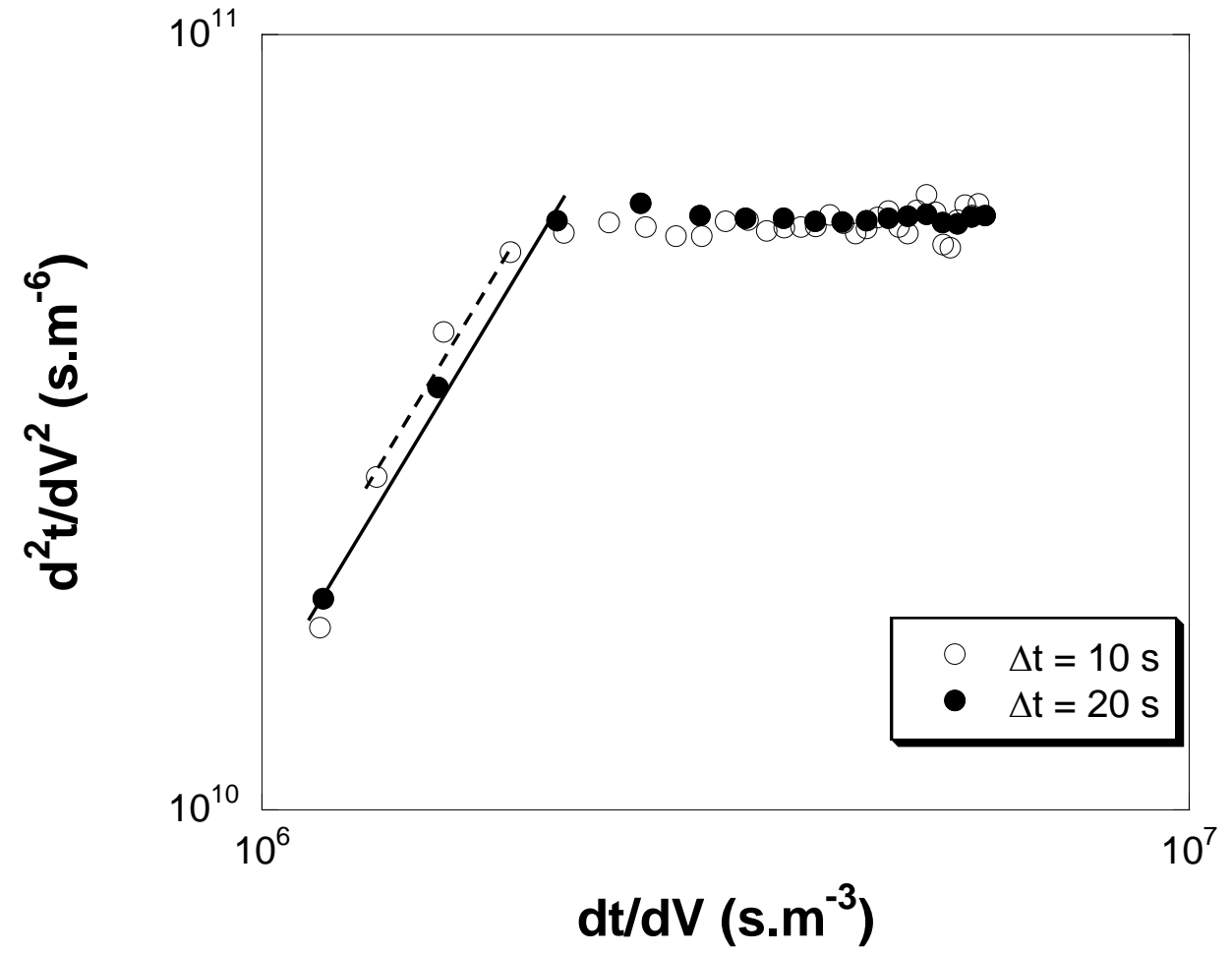

Figure 2. Influence of the time step $\Delta t$ on the $k$-value determination by using the representation for the experiment using a $0.2 \mu \mathrm{m}$ membrane $\left(C=10^{-2} \mathrm{~g} / \mathrm{L}\right.$ and $\left.\Delta P=0.3 \mathrm{bar}\right)$ 


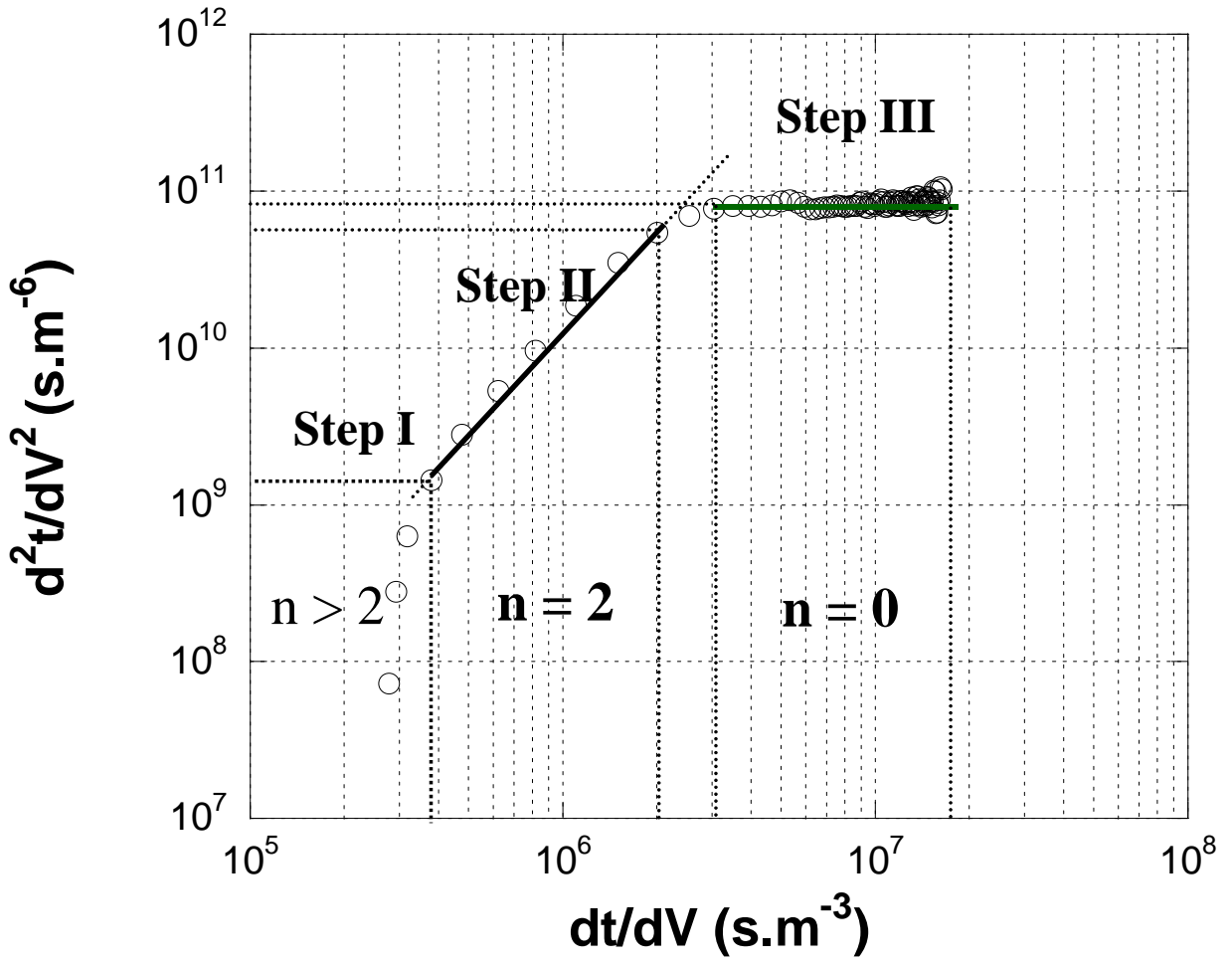

Figure 3. Example of the determination of the slope $n$ in the representation for the fouling mechanisms identification (experimental data for $5 \mu \mathrm{m}$ membrane; $C=10^{-2} \mathrm{~g} / \mathrm{L}$ and $\Delta P=0.3$ bar) 

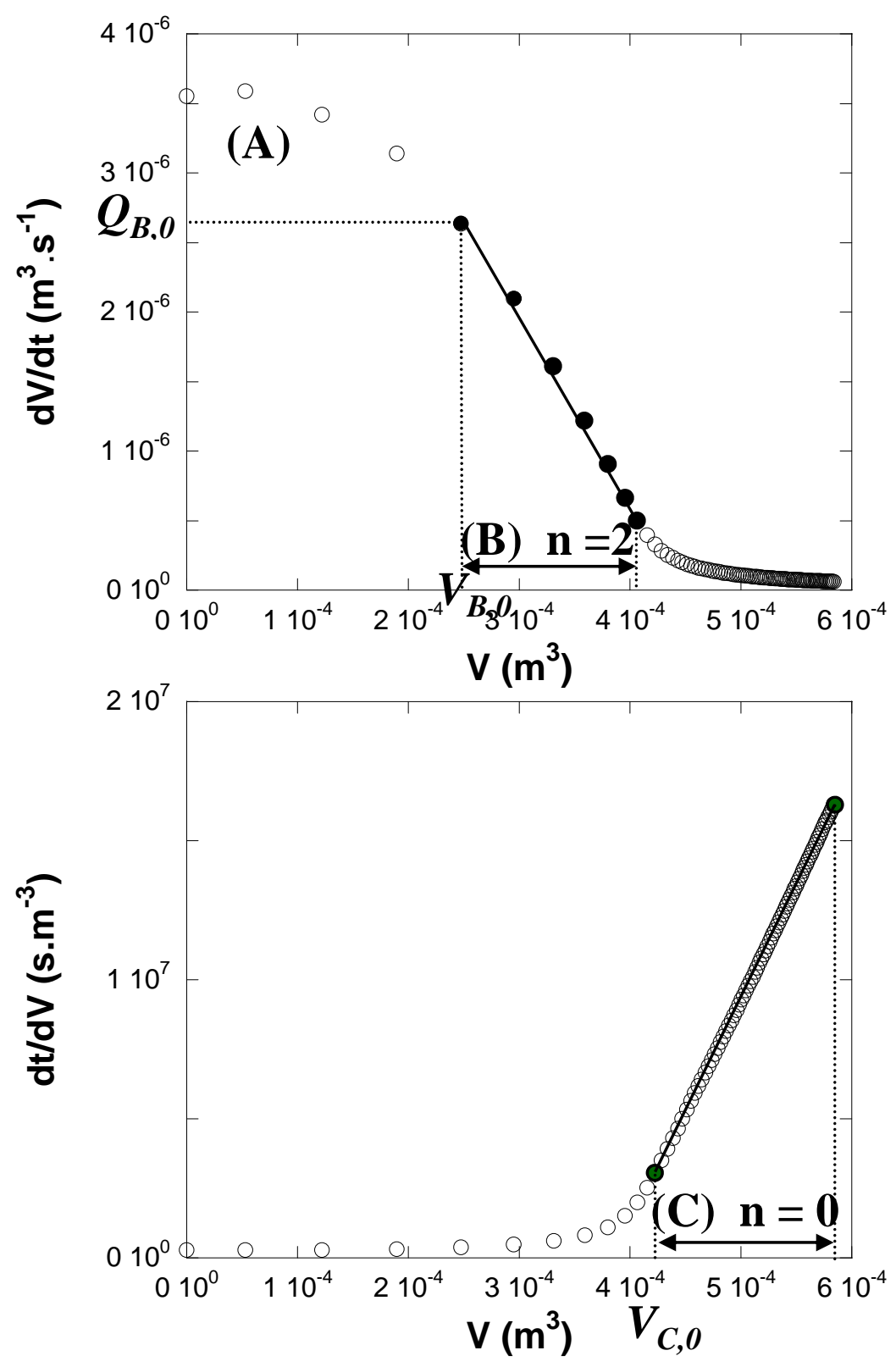

Figure 4. Split of the curves into successive mechanisms: (A) very low fouling mechanism , ( B) blocking , (C) cake filtration. 

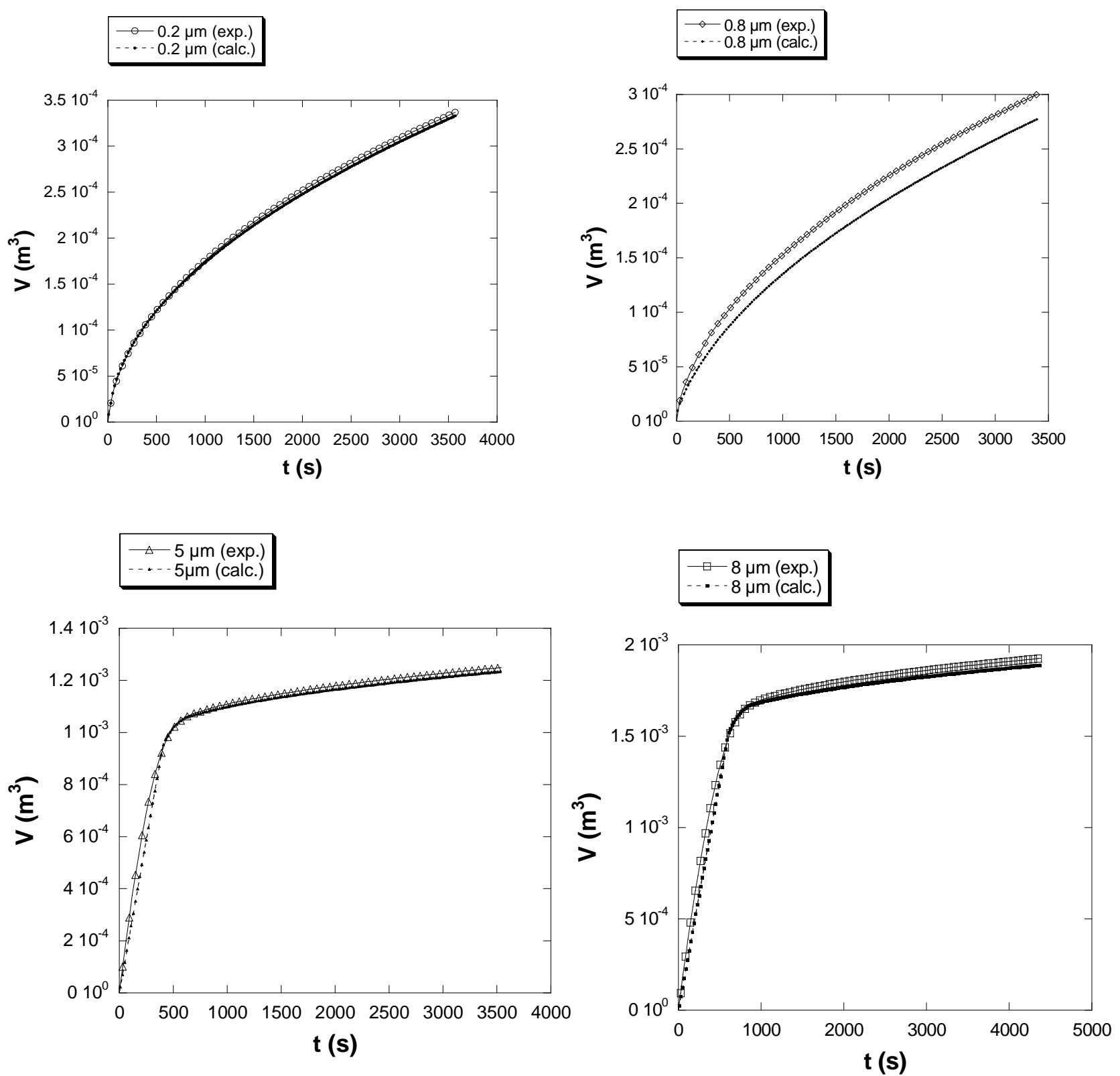

Figure 5. Plot of cumulative permeate volume $V$ versus time $t$ - comparison between experimental and calculated curves for four experiments $\left(C=10^{-2} \mathrm{~g} / \mathrm{L}\right.$ and $\Delta P=0.3$ bar): $(\bullet 0.2 \mu \mathrm{m} ; \bullet 0.8 \mu \mathrm{m} ; \mathbf{\Delta} 5 \mu \mathrm{m} ; \boldsymbol{- ~} 8 \mu \mathrm{m})$ 


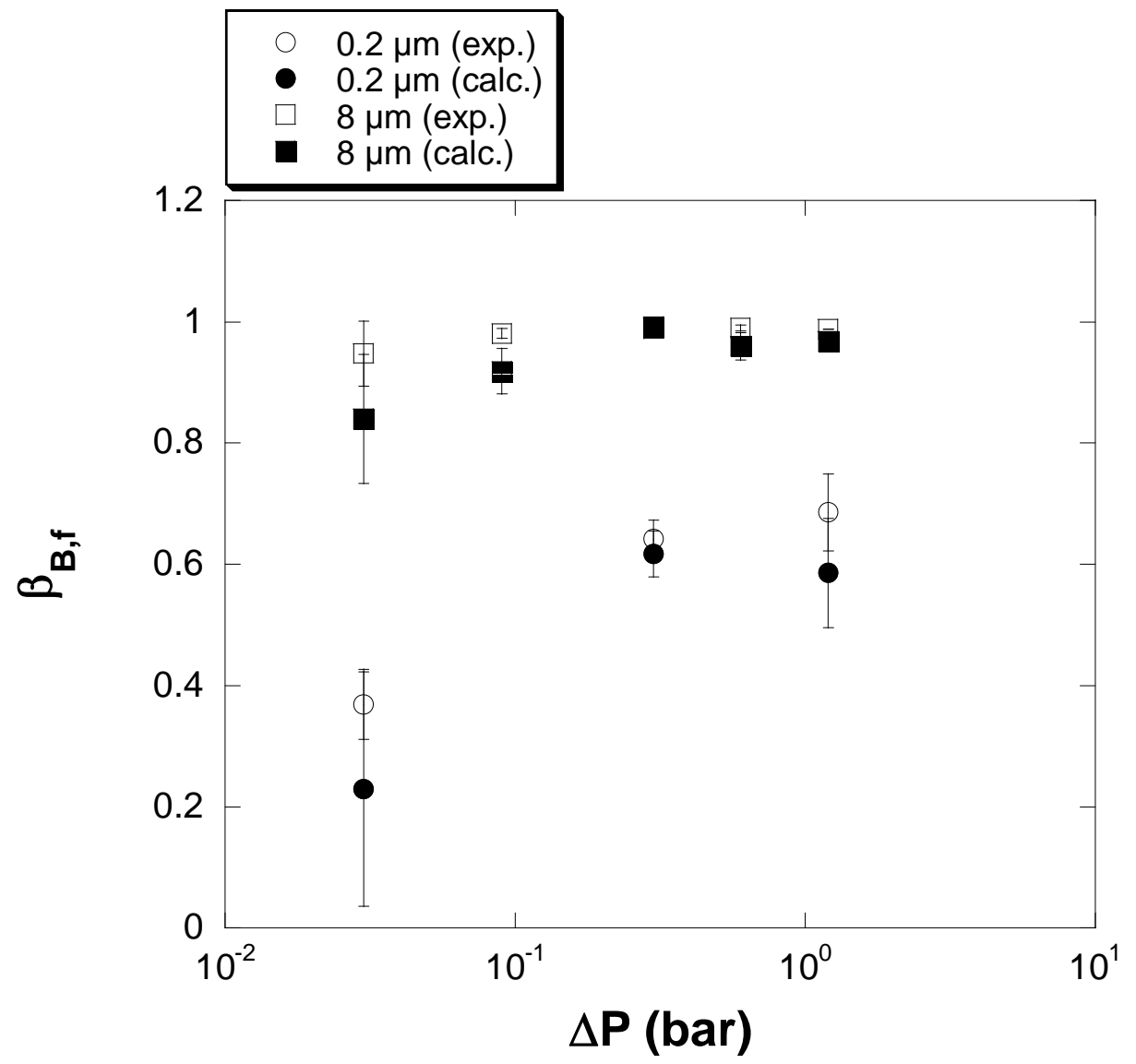

Figure 6. Effect of the transmembrane pressure $\Delta P$ on the final surface coverage ratio, $\beta_{B, f}$ for two different membranes $(0.2 \mu \mathrm{m}$ and $8 \mu \mathrm{m})$ 


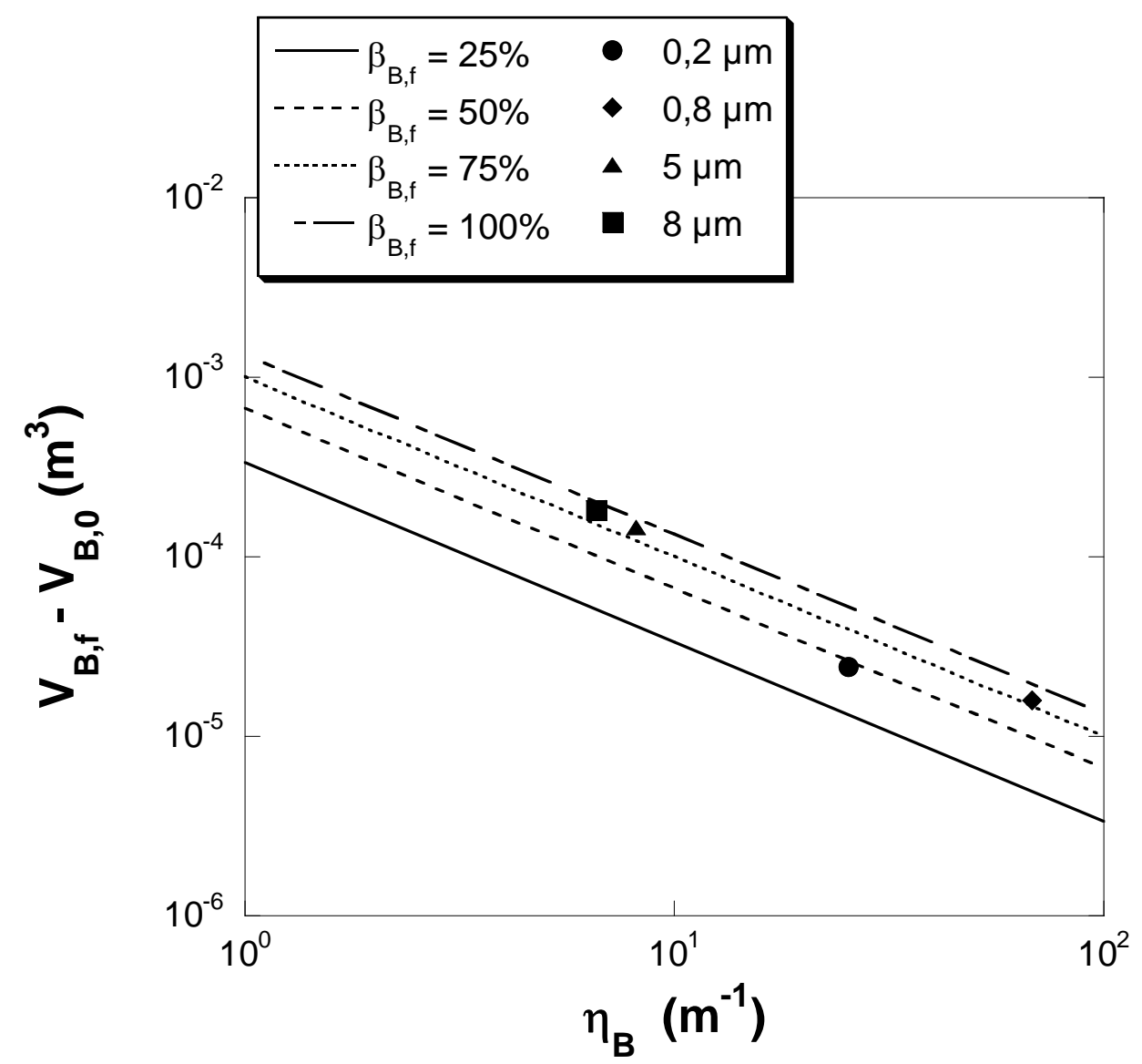

Figure 7. Symbols are the values of $\mathrm{V}_{\mathrm{B}, \mathrm{f}}-\mathrm{V}_{\mathrm{B}, 0}$ versus $\eta_{\mathrm{B}}$, for a series of data $\left(\mathrm{d}_{\text {pore }}=0.2\right.$; 0.8 ; 5 ; $8 \mu \mathrm{m})$. Operating conditions were kept the same for all these experiments: $C=10^{-2}$ g. $\mathrm{L}^{-1}, \Delta P=0.3$ bar. Lines are the calculated data of $\mathrm{V}_{\mathrm{B}, \mathrm{f}}-\mathrm{V}_{\mathrm{B}, 0}$ versus $\eta_{\mathrm{B}}$, for different values of $\beta_{B, f}$ 


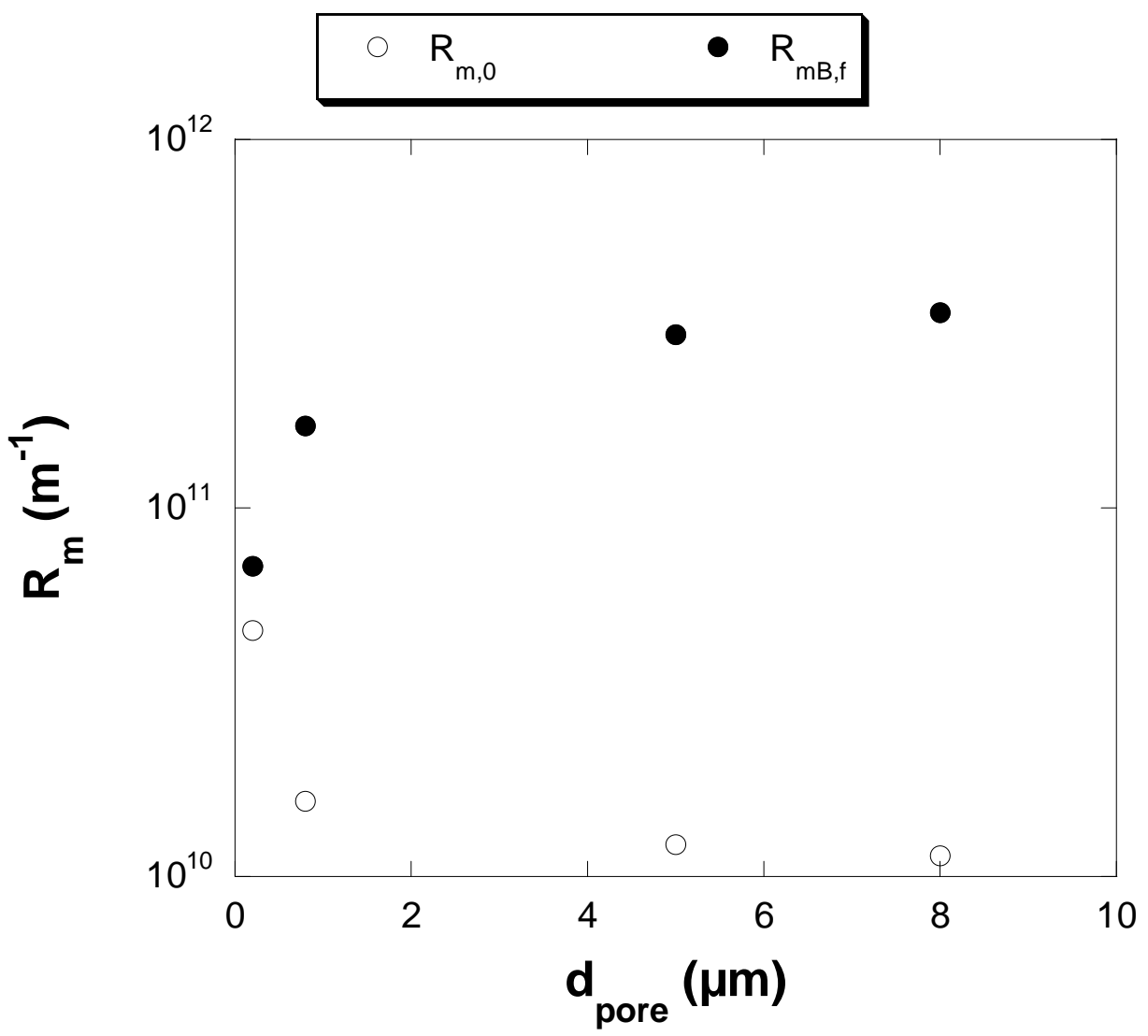

Figure 8. Evolution of a clean and fouled filter media resistance (respectively, $R_{m, 0}$ and $R_{m B, f}$ ) with its initial mean pore diameter, $d_{\text {pore }}$ 


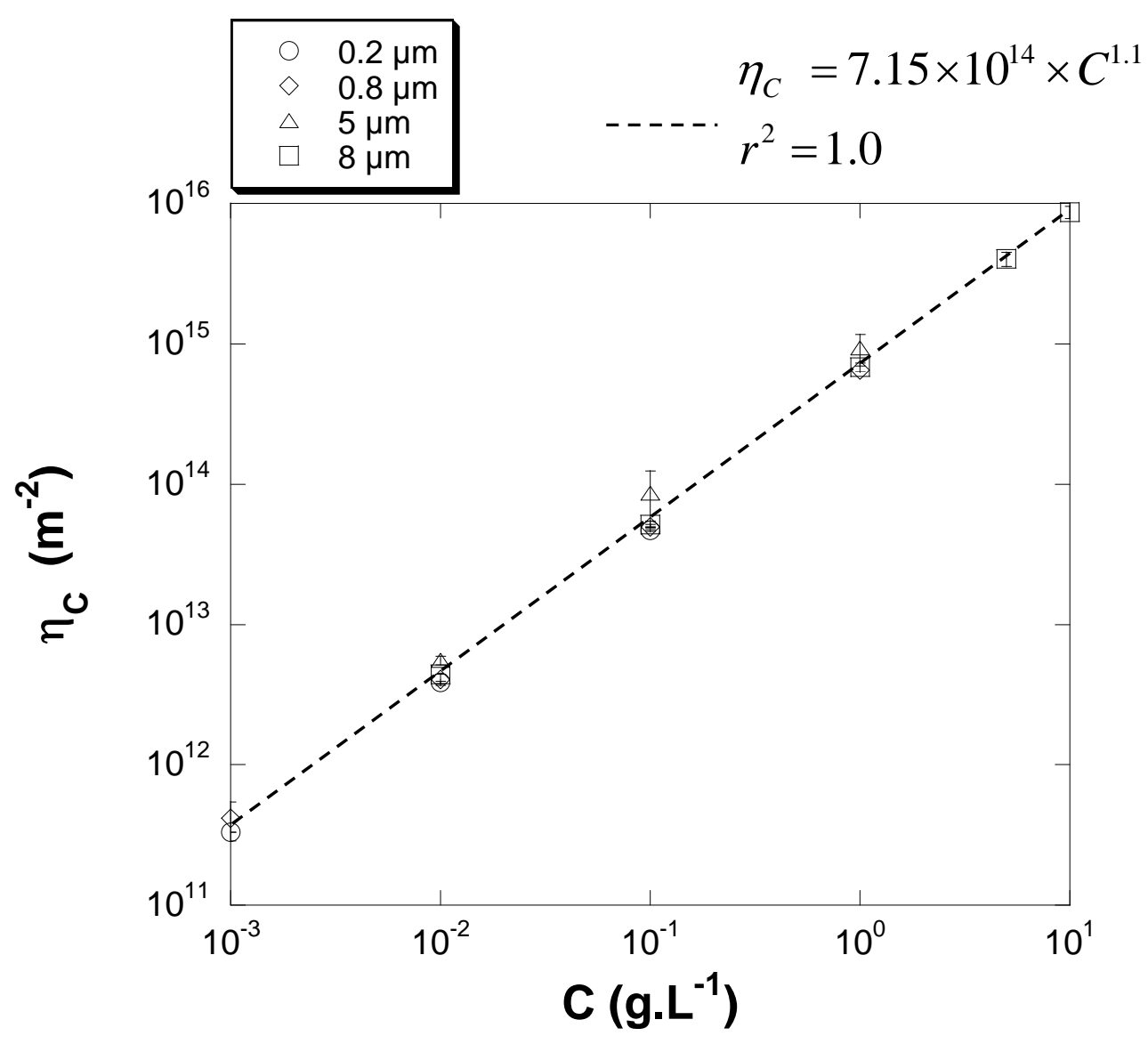

Figure 9. Effect of feed suspension concentration $C$ on the specific parameter, $\eta_{C}$, for cake formation at constant pressure $0.3 \mathrm{bar}$ 


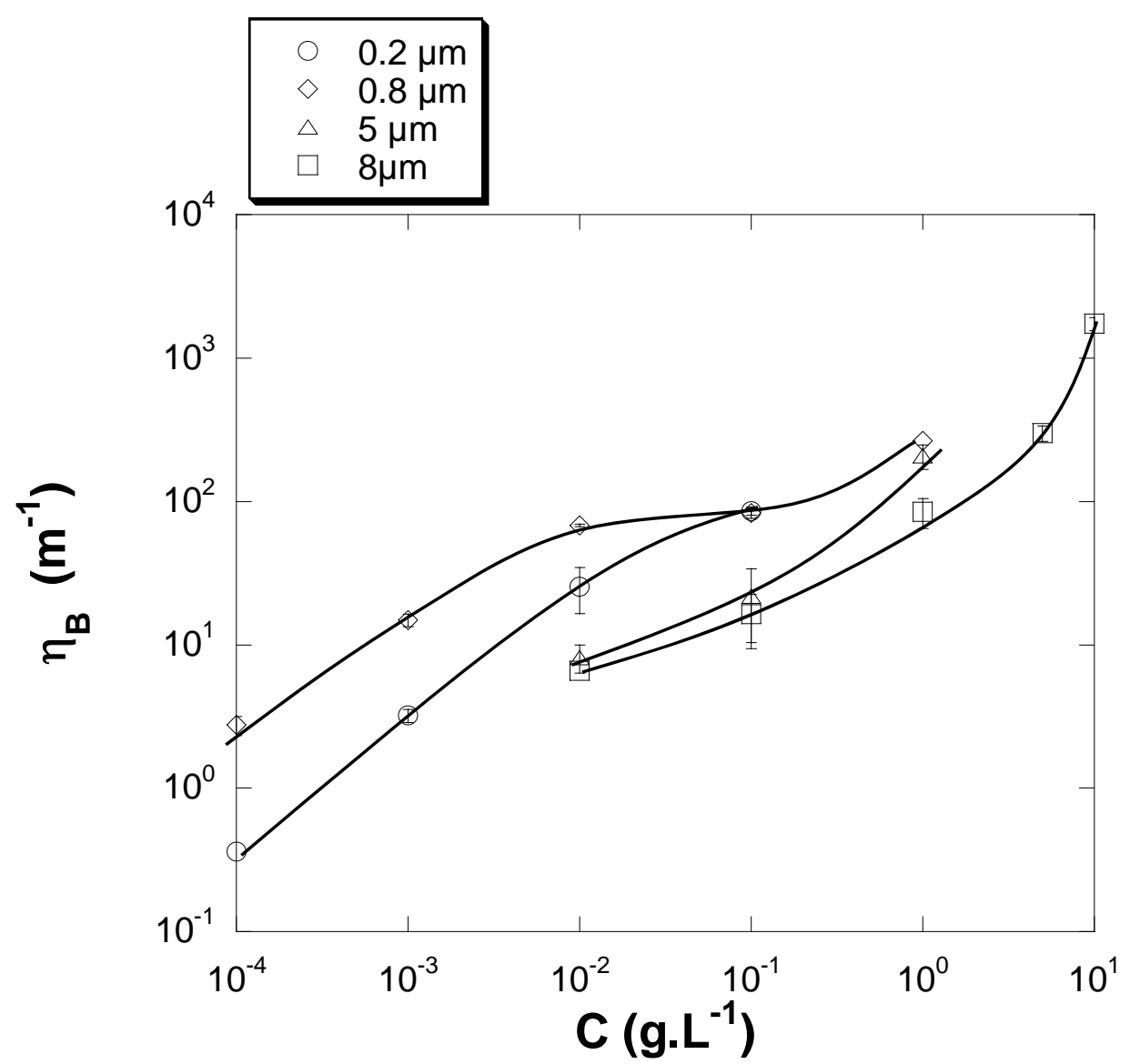

Figure 10. Effect of feed suspension concentration $C$ on the specific parameter, $\eta_{B}$, for pore blocking at constant pressure $0.3 \mathrm{bar}$ 


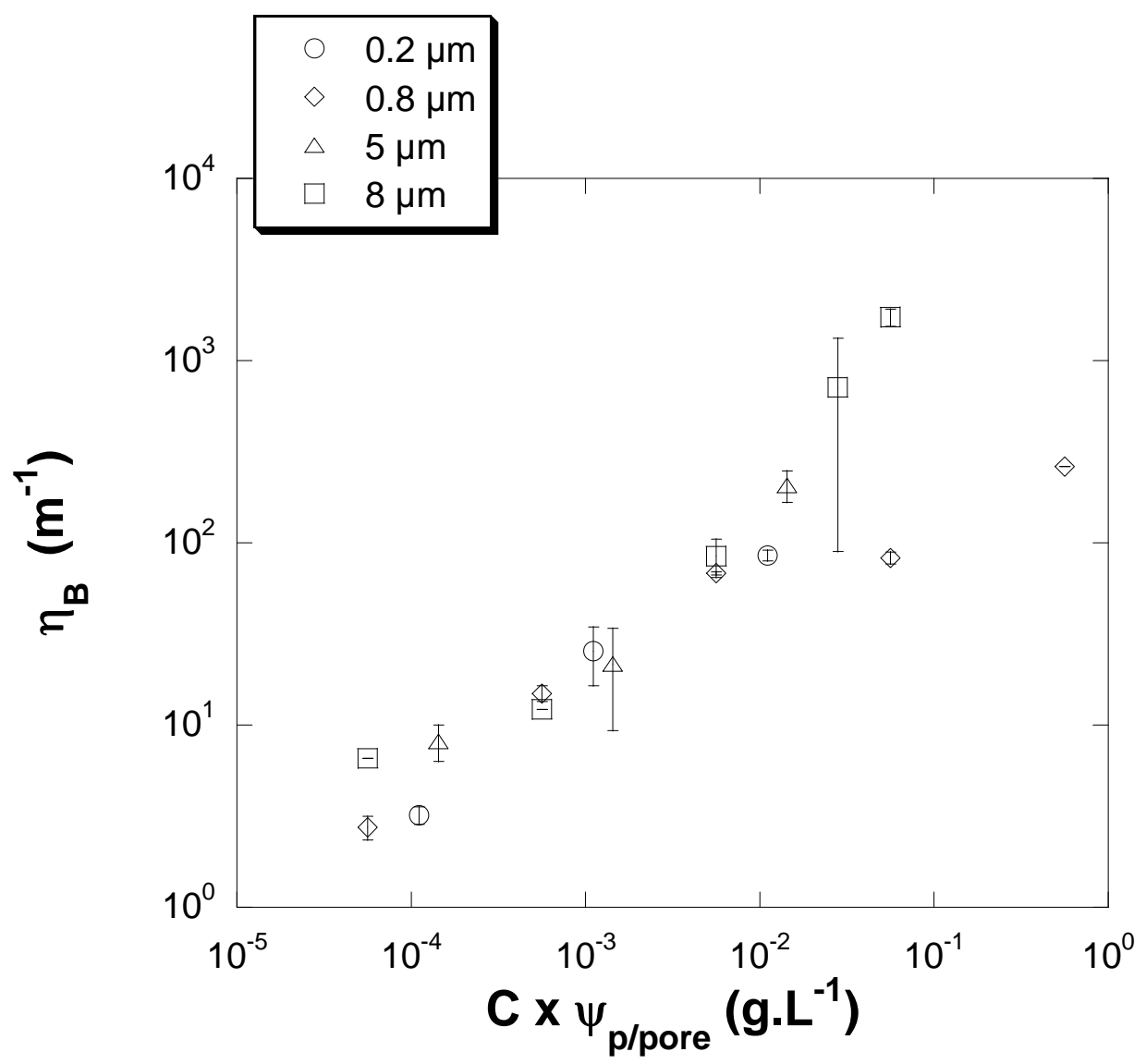

Figure 11. Plot of $\eta_{B}$ versus the product of feed concentration, $C$ times the number of blocked pores per unit of blocking particle, $\psi_{\text {p/pore }}\left(C \times \psi_{p / \text { pore }}\right)$ at constant pressure $0.3 \mathrm{bar}$ 


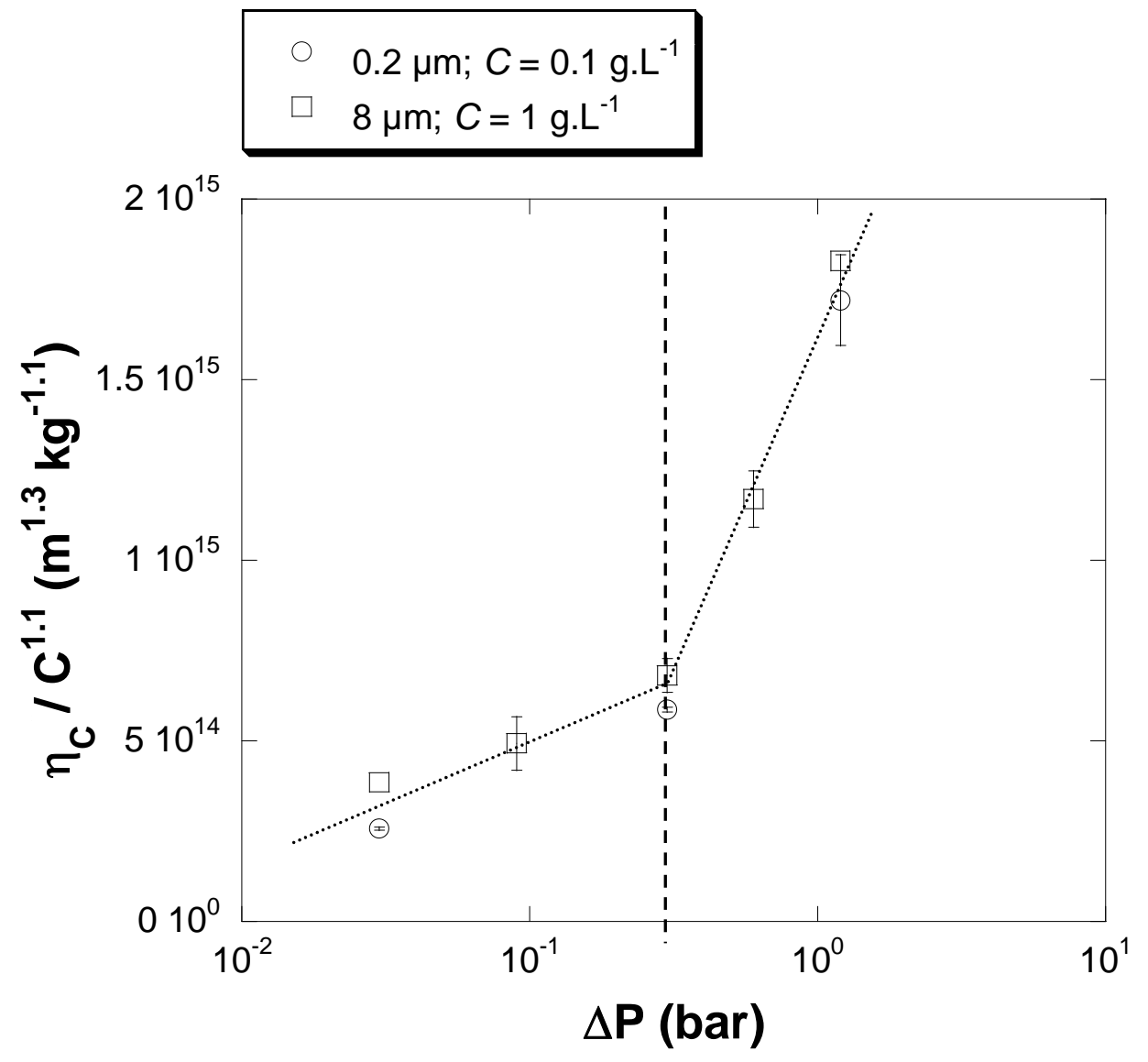

Figure 12. Effect of transmembrane pressure on cake formation: comparison between two membranes $(0.2 \mu \mathrm{m}$ and $8 \mu \mathrm{m})$ by considering the plot of $\eta_{C} / C^{1.1}$ versus $\Delta P$ 

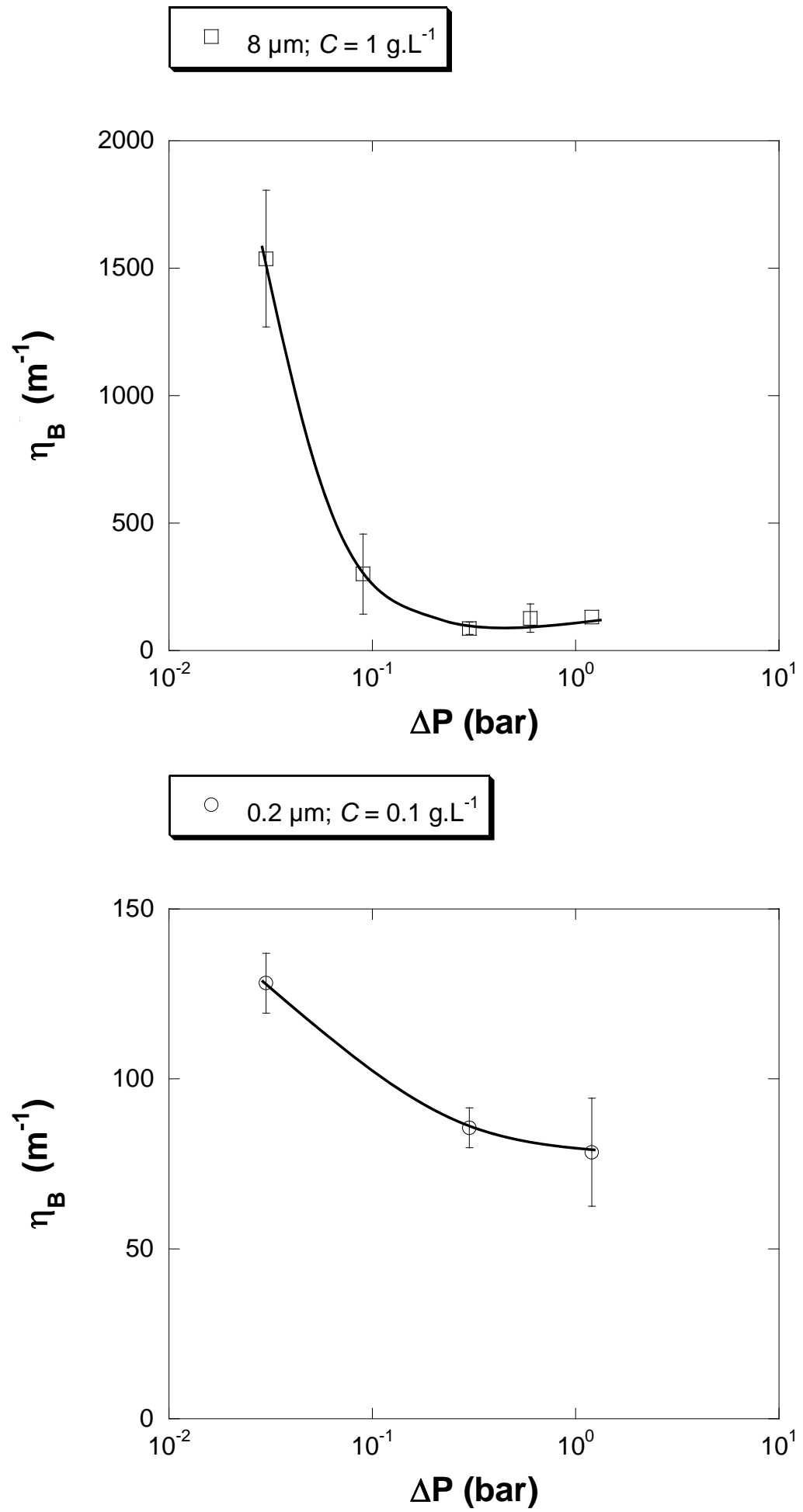

Figure 13. Effect of transmembrane pressure on pore blocking for two different membranes $(0.2$ $\mu \mathrm{m}$ and $8 \mu \mathrm{m}$ ) by considering the plot of $\eta_{B}$ versus $\Delta P$ 


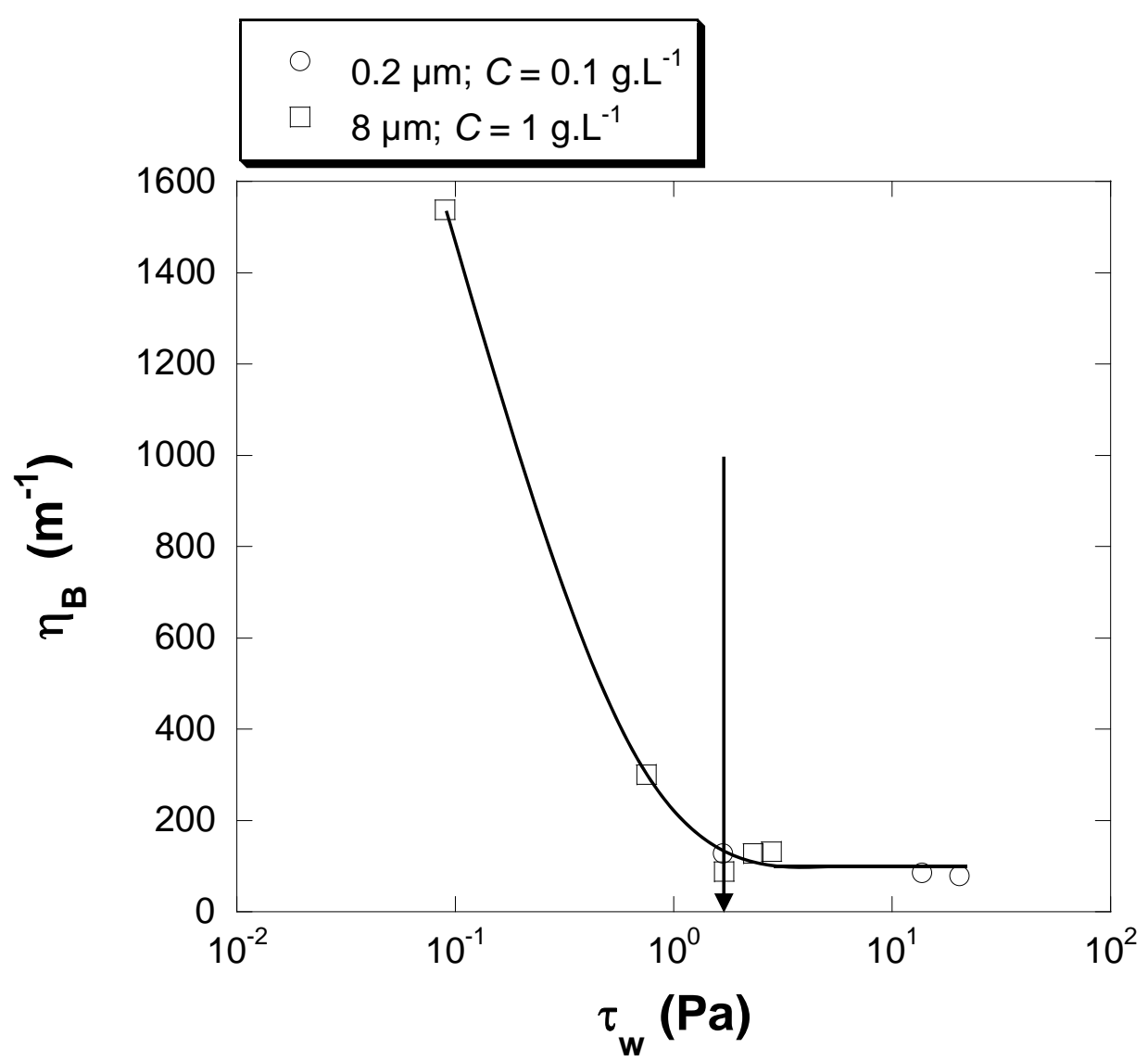

Figure 14. Effect of the wall shear stress, $\tau_{w}$ on pore blocking mechanism for two different membranes $(0.2 \mu \mathrm{m}$ and $8 \mu \mathrm{m})$ 


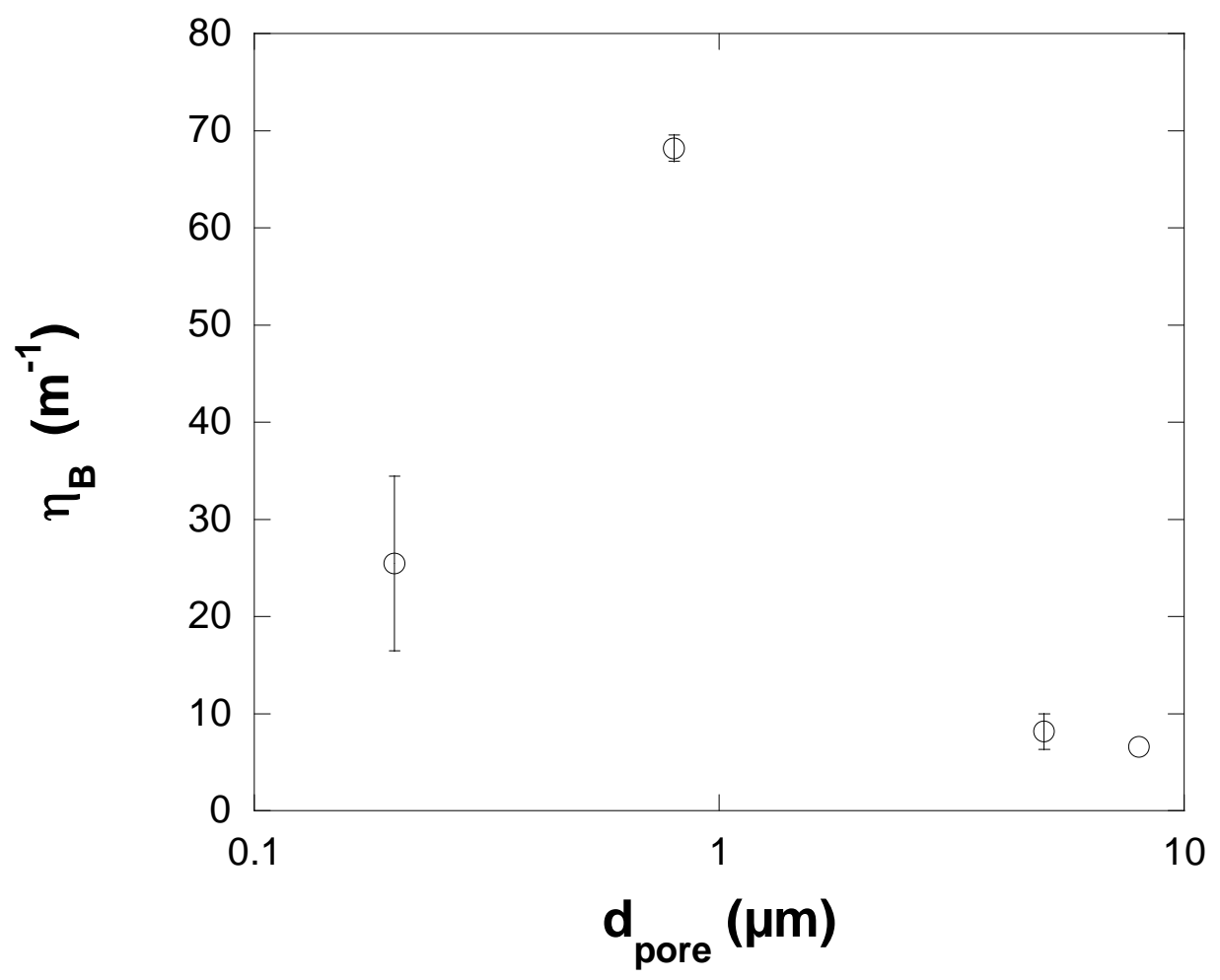

Figure 15. Effect of the mean pore diameter of the filter media on the specific parameter, $\eta_{B}$, for pore blocking $\left(C=10^{-2} \mathrm{~g} / \mathrm{L}\right.$ and $\left.\Delta P=0.3 \mathrm{bar}\right)$ 